\title{
Combinatory therapy adopting nanoparticle-based cancer vaccination with immune checkpoint blockade for treatment of post-surgical tumor recurrences
}

Chih Kit Chung a, d, C.G. Da Silva ${ }^{\text {a, }}$, Dana Kralisch ${ }^{\mathrm{d}}$, Alan Chan ${ }^{\mathrm{a}, \mathrm{b}}$, Ferry Ossendorp ${ }^{\mathrm{c}}$ and Luis J. Cruz ${ }^{\text {a, * }}$

a Department of Radiology, division Translational Nanobiomaterials and Imaging, Leiden University Medical Center, Leiden, The Netherlands

${ }^{\mathrm{b}}$ Percuros B.V., Zernikedreef 8, 2333 CL Leiden, The Netherlands.

c Department of Immunohematology and Bloodtransfusion, Leiden University Medical Center, Leiden, The Netherlands.

d JeNaCell GmbH, Winzerlaer Straße 2, 07745 Jena, Germany

* Correspondence to: Dr. Luis J. Cruz, Asst. Prof., Translational Nanobiomaterials and Imaging, Department of Radiology, Bldg.1, C2-187h. Leiden University Medical Center, Albinusdreef 2, 2333 ZA Leiden, The Netherlands. Phone: +31 715265764, Fax: +31 71 5248256; Email: 1.j.cruz_ricondo@lumc.nl

Keywords: checkpoint blocking antibodies, immunotherapy, nanoparticles, surgery, therapeutic cancer vaccines, tumor microenvironment 


\section{Graphical abstract}

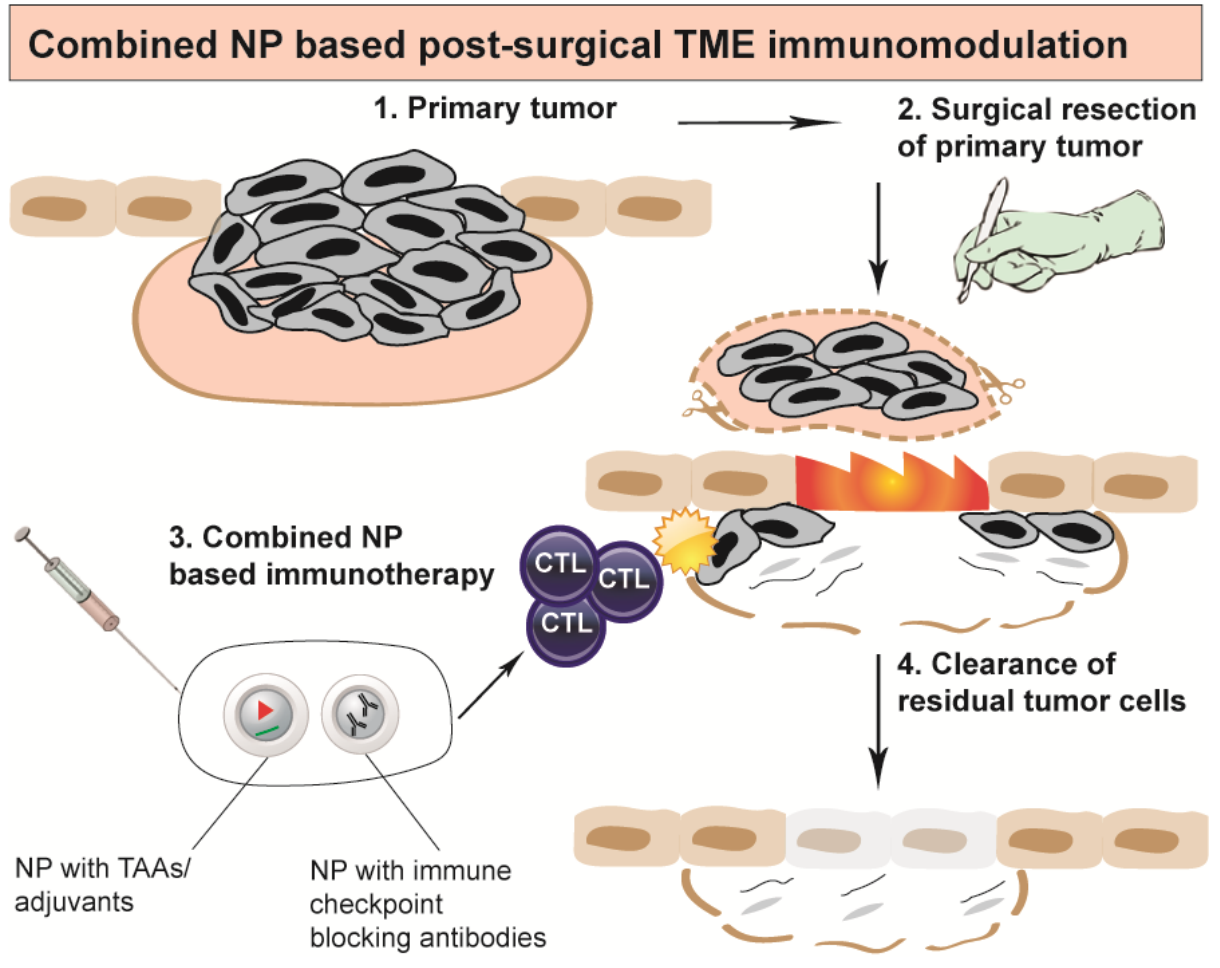




\begin{abstract}
Cancer immunotherapy is emerging as a candidate treatment modality for treating postsurgical metastasis and recurrences. Despite the great promises with therapeutic cancer vaccines and checkpoint blocking antibodies in pre-clinical studies, response rates in the clinic still remain unsatisfactory. The evaluation of immunotherapy after surgery in patients could confront significant unexpected hurdles. Surgery itself tends to cause immune suppression, while wound healing factors also stimulate tumor cell outgrowth and metastasis. Regarding the marked changes in the post-surgical tumor microenvironment, one can anticipate that better tumor growth control is attainable by combining cancer vaccines with immune checkpoint blockade. However, it is important that vaccines and checkpoint blocking antibodies are delivered efficiently to their target cells, are released sustained and locally and do not induce cytotoxic effects. The generation of effective anti-tumor immunity and durable response rates could largely depend on these parameters. In the last decade, researchers spend tremendous effort in optimizing the delivery of immunotherapeutic compounds with the use of nanomedicine. Biocompatible nanoparticle based delivery systems demonstrated intriguing results with regard to specific immune cell activation, improved drug delivery, cell targeting, limiting off target toxicity and improving treatment outcome. It therefore makes sense, to speculate on the promises of combined cancer vaccination and immune checkpoint blocking immunotherapy with the aid of nanomedicine. A powerful nanoparticle combination immunotherapy conferring durable therapeutic benefit whilst leaving healthy tissue untouched represents the base for more efficient post-surgical cancer treatment.
\end{abstract}




\section{Introduction}

Cancer is a worldwide leading cause of mortality following cardiovascular diseases[1]. Although surgery represents the conventional way to remove the primary tumor mass, its notorious limitation is the omission of residual and occult tumor cells. These often progress into relapses and metastasis, thereby accounting for the majority of cancer deaths[2, 3]. To prevent this from occurring, (neo)adjuvant therapies including hormone, chemo- and radiotherapy are often provided. Unfortunately, these modalities bear certain short-comings, including off-target toxicity, treatment resistance and marginal response rates $[4,5]$.

In meantime, therapeutic cancer vaccines (TCVs) and checkpoint blocking antibodies (CBAs) are emerging as promising immunotherapeutic treatment modalities for the prevention of post-surgical tumor recurrences. Immunotherapy explores the body's own immune system to fight cancer cells and features a promising strategy to prevent postsurgical tumor recurrences[6-8]. Unfortunately, clinical trials evaluating TCVs and CBAs for the treatment of post-surgical cancer recurrences have mostly not yielded convincing results so far. The clinical evaluation of immunotherapy with regard to surgery has confronted numerous challenges. It is apparent that the complex interplay between surgery, anti-tumor immunity and tumor pathophysiology has not been adequately considered during the design of immunotherapies. Surgery tends to exert immunosuppressive effects, while wound healing factors induce unfavorable immune phenotypical alterations in recurring tumors. Omitting these factors putatively lead to inadequate evaluation and design of (neo)adjuvant immunotherapies in the clinic. This could explain why certain clinically evaluated TCVs failed to prevent post-surgical tumor recurrences, although they could generate $\mathrm{T}$ cell responses[9]. The marked immunosuppressive effects of surgery and the post-surgical tumor microenvironment (TME) tend to dampen $\mathrm{T}$ cell function and viability. Considering these hurdles, combination immunotherapies concomitantly targeting immunosuppressive and immunostimulatory pathways are putatively more effective to halt tumor outgrowth. Combined vaccination with TCVs together with immune checkpoint blockade is deemed to harness these synergistic effects. Additional immune stimulation from CBAs that alleviate immune suppression and restore $\mathrm{T}$ cell function may strongly potentiate the $\mathrm{T}$ cell responses, which may break the immunosuppressive post-surgical TME barrier.

Whilst combination immunotherapies portray promising concepts for halting tumor progression, particular combinations could trigger systemic immune related side effects (IRAEs). Moreover, drug release control, cumbersome treatment schedules and poor therapeutic efficiency could raise treatment costs. In this regard, the field of nanomedicine 
has spent tremendous effort on optimizing nanomaterial based drug delivery systems to tackle these issues. Recent advances in nanomedicine elegantly underscored the promises of nanoparticle (NP) assisted immunomodulation. Important focus points of nanomedicine based immunotherapy encompass the improvement of drug bioavailability, extension of immune cell activation, targeting of specific (immune) cells and prevention of systemic drug delivery to healthy tissues[10-12].

This review will highlight the complex tumor-immunological changes in the post-surgical TME. Combination therapies with TCVs and CBAs can confer synergistic effects to achieve more powerful TME immunomodulation, but require further improvement. We will focus on the recent advances of NP based immunotherapy, and speculate on the benefits of combined TCV and CBA immunomodulation with the aid of nanomedicine.

\section{The challenges of applying immunotherapy in combination with surgery}

2.1. The role of $\mathrm{T}$ cell immunity in protecting against post-surgical tumor recurrence The human immune system orchestrates pivotal functions in the defense against invading pathogens and detection and elimination of cancerous cells, a theory referred to as 'immune surveillance' by Burnet[13, 14]. Although 'immune surveillance' is accepted as a mostly Tcell mediated controlling system that protects our body for malignancies, it is obvious that this system has failed in cancer patients. In these patients it has been shown that there are tumor-specific $\mathrm{T}$ cells present, but these are generally in a tolerized state mainly caused by the suppressive TME and immune escape[15]. Current immunotherapies aim to re-activate these tumor-specific T cells to attack and eliminate malignant cells. There are several types of immune responses. Cytotoxic CD8 $\mathrm{T}$ lymphocyte (CTL) responses mainly targeted to specific intracellular epitopes presented on the MHC-I of (cancer) cells, are efficient to eliminate cancer cells. A T-helper 1 (TH1) type immunity is mediated by CD4 T helper 1 cells of the adaptive immune system and is commonly initiated by antigen presenting cells (APCs), which can orchestrate an effective CD8 T cell response. Dendritic cells (DCs) are APCs with superior capacities to process antigens and present them to (naïve) CD4 and CD8 T cells via MHC-II and I molecules, respectively[16]. Specific damage-associated molecular patterns or pathogen associated molecular patterns danger signals can trigger DCs to initiate a skew towards a TH1 type of response. These danger signals stimulate DCs to upregulate the 
expression of co-stimulatory molecules including CD40, CD80 (B7.1), CD86 (B7.2) and MHC-I/II molecules and to produce TH1 cytokines, such as interleukine-12 (IL-12) and interferon gamma (IFN- $\gamma$ ). These TH1 polarizing signals are necessary to effectively prime naïve CD4 T cells into TH1 cells[17, 18]. TH1 cells and DCs form subsequent cognate pairs with naïve CD8 T cells to develop them into CTLs, which then enter the blood to seek and destroy cancer cells.

A TCV is regarded as a treatment modality that aims to stimulate an immune response to fight existing cancers[19-21]. Tumor cells are typically hallmarked by the expression of tumor associated antigens (TAAs) and tumor antigens. Vaccinating with adjuvants and antigen stimuli can induce DC maturation to onset tumor specific CTL responses to eliminate cancer cells[22]. Notably the cancer testis antigens (BAGE, MAGE, NY-ESO), tissue differentiation antigens (gp100, Melan-A/MART-1) and oncofetal antigens (MUC-1, CEA) have been extensively explored as targets for TCVs. Rather than delivering a single antigen, TCVs could also contain whole tumor cells. A well-known example is GVAX, that consists of whole tumor cells secreting granulocyte-macrophage colony-stimulating factor (GM-CSF). This TCV recruits and maturates DCs for effective priming of CTLs and is especially evaluated in pancreatic cancer patients[23-25]. In a comparable way, OncoVAX® consists of autologous tumor cells supplemented with Bacillus Calmette-Guerin adjuvant and has been evaluated in patients with stage II and III colorectal cancer and was notably effective in stage II patients[26].

CTLA-4 and PD-1 are inhibitory checkpoint molecules, which activation leads to $\mathrm{T}$ cell activity inhibition. They further tend to promote regulatory $\mathrm{T}$ cells (Tregs) development, albeit the exact mechanisms remain elusive[27, 28]. Their functional opposites are immunostimulatory checkpoint molecules, such as CD40, OX-40 and 4-1BB. CTLA-4 binds to $\mathrm{CD} 80$ and CD86 similar to CD28, although with considerably higher affinity. CTLA-4 transmits inhibitory signals in $\mathrm{T}$ cells and is functionally the opposite of CD28[29]. The cognate ligands for PD-1 are PD-L1 and PD-L2, which are often found overexpressed by (tumor) cells in the TME, including tumor associated macrophages (TAMs), tumor associated DCs, fibroblasts and Tregs. PD-L1 or PD-L2 binding to PD-1 induces T cell anergy or apoptosis[30-32]. Not surprisingly, inhibitory checkpoint molecules are regarded as appealing targets to restore effector T cell function[7, 33]. Ipilimumab (Yervoy®) is an antiCTLA-4 antibody approved by the FDA in 2011 for the treatment of metastatic melanoma[34]. A PD-1 blocking antibody Nivolumab is approved for treating melanoma and non-small cell lung carcinoma since 2015[35-37]. Ipilimumab was recently evaluated as post- 
surgical therapy for resectable stage III cutaneous melanoma in a double blind phase III trial and significantly prolonged relapse-free survival (RFS) and overall survival (OS)[38, 39].

At the end of the previous century, it was apparent that the immune system could reduce post-surgical cancer recurrences. Háková et al.[40] evaluated IL-2 gene therapy as postsurgical immunotherapy in mice bearing MK16 carcinomas. While tumor recurrence rate in the operated-only mice was $90 \%$, recurrence rate was $38.5 \%$ in mice receiving also IL-2. After approximately 50 days, splenocytes were collected, cultured further in IL-2 containing medium and analyzed for splenocyte activity. Splenocyte activity was considerably higher in mice that remained free of tumor relapses. Natural killer (NK), CD4 and CD8 T cell depletion abrogated the effects of post-surgical IL-2 treatment. In their follow-up study, the authors evaluated IL-2, IFN- $\gamma$ and granulocyte-macrophage colony-stimulating factor (GMCSF) as cytokine therapy after surgical resection of HPV16-associated tumors (TC1 and MK16)[41]. Splenocyte cytolytic activity was significantly higher in mice free of relapses, but this result was irrespective of the adjuvant treatment and tumor type.

In pre-clinical studies, immunotherapies stimulating the TH1 type response demonstrated great promises as potential cancer treatment. Various therapies were further explored in the clinical setting for different cancer types. Although some TCVs improved OS and RFS following surgical resection of melanomas[42-44], results were not convincing in other trials and cancer types[45-47]. Several reasons may underlie the discordance between pre-clinical studies and clinical trials.

2.2. Surgery suppresses TH1 type immunity and induces profound cellular and cytokine changes in the post-surgical TME

Surgery could affect local and systemic immunity and tumor pathophysiology[48]. Whilst immunotherapies have been thoroughly evaluated in a variety of murine tumor models, these models often did not introduce any surgical variables. It may not be adequate to directly translate results obtained from non-surgical studies to the surgical clinic. Surgery is a large stressor and stimulates the hypothalamic-pituitary-adrenal (HPA) axis and the release of stress hormones, notably glucocorticoids and corticosterones, while also increasing sympathetic nervous outflow and the release of (nor)adrenaline. These 'fight-or-flight response' hormones have immunosuppressive properties. Surgical stress could further induce tumor vascularization and tumor cell dissemination, mainly via angiogenesis, with VEGF as the main regulator[49-51]. In response to surgical stress and anesthesia, cancer cells are also more prone to escape immune attack and tend to possess enhanced survival and proliferative 
capacity[52]. Table 1 provides an overview of some effects that surgery could exert on immunity.

\section{Table 1}

Surgical induced stress can exert numerous effects on the immune system

Effect of surgery Ref.

Adrenaline $\uparrow$ which in turn decreases IL-2 production

Decrease in neutrophil and macrophage numbers/mobility

Decrease in NK cell numbers and function

Decrease in numbers of circulating $\mathrm{T}$ cells and proliferation

$[53, \quad 59-$

$61]$

Decrease of TH1 type of cytokine production (i.e. IL-2, IL-12, IFN- $\gamma$, TNF- $\alpha$ )

Increase in anti-inflammatory gene expression (i.e. lipocortin-6, IL-1,

IL-10, neutral endopeptidase)

Anesthesia and analgesia induced general immunosuppression

[65-68]

Only a few pre-clinical studies have explicitly assessed immunotherapy in the context of tumor resection. In these studies, subcutaneous tumors were established and the entire tumor could be easily resected. However, this may not be a realistic representation of tumor recurrence in patients, since residual tumor cells are often omitted[48]. These cells reside in the post-surgical wound and may be influenced by surgical stress, wound healing and inflammatory mediators. Predina et al.[48] introduced an interesting post-surgical tumor recurrence model that for the first time introduced considerably more surgical variables representative for human surgery. The novelty in this study was that the authors left behind a small portion (margin) from subcutaneously growing tumors at the site of resection. Some studies revealed a rise of wound and inflammatory mediators, including TGF- $\beta$, COX-2, 
prostaglandins and VEGF in the post-surgical TME[69, 70]. These mediators can promote tumor cell outgrowth and suppress anti-tumor immunity, i.e. by exhausting $\mathrm{T}$ cells, impairing $\mathrm{T}$ cell infiltration, and promoting the development of Tregs and myeloid-derived suppressor cells (MDSCs)[71]. Furthermore, Tregs in dormant tumor tissue may also contribute to tumor recurrence[72]. Indeed, the administration of TGF- $\beta$ and COX-2 inhibitors effectively led to the cessation of tumor growth, but also affected wound healing. In their following study[73], the authors evaluated various TCVs in mice that underwent surgical resection of subcutaneous tumors. The TCV-induced $\mathrm{T}$ cell responses were effective to clear tumor cells from primary, non-resected tumors. However, these $\mathrm{T}$ cell responses were infective to halt outgrowth of tumors recurring at the surgical area. TME and tumor draining lymph nodes (TDLNs) analysis of these recurring tumors revealed higher numbers of wound healing macrophages (type 2 macrophages; M2), TAMs and Tregs, but lower numbers of tumor infiltrating T cells (TILs). This was accompanied by a decrease of IFN- $\gamma$ and a rise of IL-6, IL-10 and VEGF. Besides wound healing factors, platelets covering the surgical wound could also trigger inflammation and metastasis. Interestingly, Wang et al.[74] utilized platelets as delivery system for immunotherapeutics. The authors conjugated PD-L1 blocking antibody to platelets, and the release of PD-L1 blocking antibody reduced post-surgical tumor recurrence in mice bearing B16F10 melanoma and 4T1 (murine tumor model for metastatic breast cancer) tumors. Platelets delivered the bound PD-L1 blocking antibody to the surgical area, which also reached circulating cancer cells.

Above discussion highlights the unwanted general decrease of TH1 type immunity and reveal certain cumbersome hurdles for the design of immunotherapies to treat post-surgical recurrences. Surgery affects immunity and commonly promotes the formation of an immune suppressed environment that is necessary to allow wound healing to occur. But this wound healing environment is also a favorable environment for residual cancer cells to grow and metastasize unhampered, thereby representing a large risk for developing tumor relapses (see Fig. 1). 


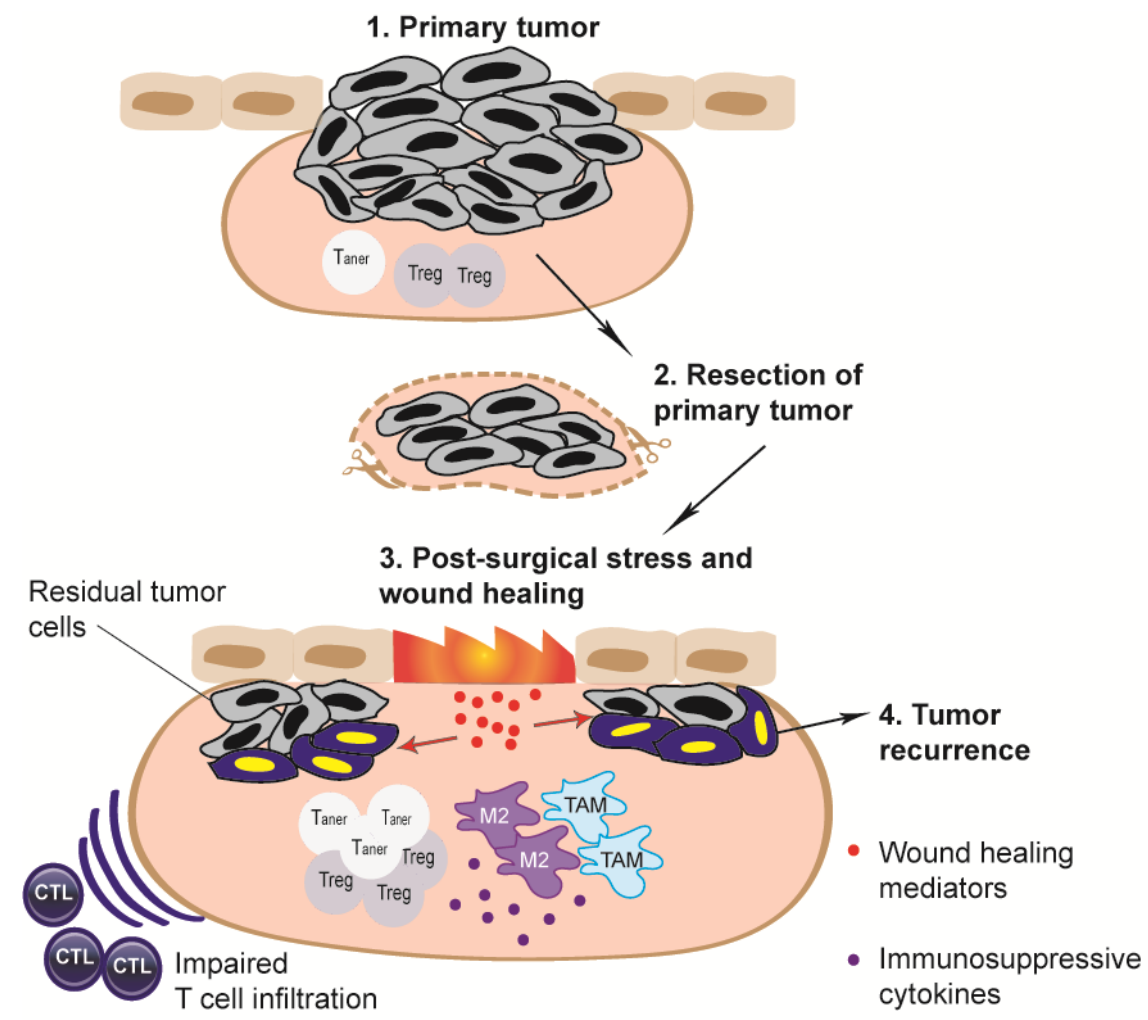

Fig. 1. Profound cytokine and cellular changes in the post-surgical TME. Surgery induces local tissue/skin damage, resulting in the production of wound healing and inflammatory factors. These factors could potentiate the outgrowth and metastasis of residual tumor cells. The post-surgical TME is furthermore enriched in Tregs, Taner, M2 and TAM type of macrophages. These profound cytokine and cellular changes typically favor the outgrowth of omitted residual cancer cells, whilst antagonizing CTL infiltration and anti-cancer TH1 type of immunity. Abbreviations: CTL: cytotoxic T lymphocyte; M2: type 2 macrophage; TAM: tumor associated macrophage; Taner: anergic T cell; TME: tumor microenvironment; Tregs: regulatory T cells.

Omitting these insights may lead to inaccurate evaluation and design of post-surgical immunotherapies in the clinic, which may - at least in part - explain the marginal outcomes in earlier clinical trials. Whilst TCVs could generate substantial CTL responses sufficient to contain the outgrowth of naïve tumors in mice, these may succumb to the profound immune dampened and wound healing post-surgical TME of patients. More effective immunomodulation is likely attainable by combining immunotherapies, that (re-)shape the TME in such way, that it favors anti-tumor immunity while leaving wound healing unhampered. There is rationale to concomitantly generate effective CTL responses while 
alleviating immunosuppression on immune cells, which effect could be attained by combining TCVs and CBAs.

2.3. Combined cancer vaccination and immune checkpoint blockade for synergistic TME immunomodulation

Early studies demonstrated how GVAX, a TCV composed of whole tumor cells genetically modified to produce the cytokine GM-CSF, synergized with CTLA-4 blocking therapy in poor immunogenic melanoma and prostate cancer[75-77]. Importantly, combined TCV and CBA treatment modulates the TME by depleting intratumoral Treg populations, while expanding $\mathrm{T}$ effector cell populations[78-81]. In a similar way, CTLA-4 blockade on both CTLs and Tregs confers the full therapeutic effects of CTLA-4 blockade[82]. PD-(L)1 blockade exerts comparable immunological effects[83-87]. Pancreatic tumors with weak PDL1 expression are often resistant for PD-1 blockade. Soares et al.[86] demonstrated that GVAX enhanced PD-L1 expression in pancreatic tumor bearing mice. Combined with PD-1 blockade, GVAX elevated the number of TILs and IFN- $\gamma$ concentration in the TME, while abolishing immunosuppressive pathways. Lutz et al.[88] demonstrated that TCVs sensitized a poor immunogenic murine pancreas tumor for CBA therapy. These results were extended into a clinical trial, where the GVAX vaccine together with cyclophosphamide (a Treg depleting compound) were administrated prior to surgical debulking of pancreatic ductal adenocarcinomas. Examination of resected tumors revealed a higher TIL-Treg ratio in vaccinated patients but also increased PD-L1 expression, which increased sensitivity to PD-1 blockade[89]. A noteworthy observation in patients is that CBAs are mostly effective against melanomas or non-small cell lung cancer (NSCLC). A plausible explanation for this phenomenon is that these cancer types harbor many immunogenic (point) mutations, thereby yielding neo-epitopes[90, 91]. These cancer types attract more TILs and in fact trigger a baseline endogenous anti-tumor immune response[92, 93]. It is speculated that CBAs synergize with the intrinsic $\mathrm{T}$ cell responses against the melanoma epitopes, while poor immunogenic tumors are often resistant to CBA therapy. In the clinic, numerous clinical trials are finished or planned that combine TCVs with ipilimumab or nivolumab for postsurgical immunomodulation (Table 2).

\section{Table 2}

Overview of trials combining ipilimumab or nivolumab with cancer vaccines 


\begin{tabular}{|c|c|c|c|}
\hline Cancer type & Regimen & Readout/analysis & Reference/trial ID \\
\hline $\begin{array}{l}\text { Resectable } \\
\text { melanoma stage, }\end{array}$ & $\begin{array}{l}\text { Ipilimumab + } \\
\text { gp100/Tyros/MART-1 }\end{array}$ & OS, RFS & [94] \\
\hline IIIc/IV & & TAA specific CTLs & \\
\hline $\begin{array}{l}\text { Resectable } \\
\text { melanoma, stage }\end{array}$ & $\begin{array}{l}\text { Nivolumab + NY-ESO-1 } \\
\text { /gp100/MART-1 multi-peptide }\end{array}$ & OS, RFS & [95] \\
\hline IIIc/IV & vaccine & $\begin{array}{l}\text { TAA specific CTLs and } \\
\text { THs }\end{array}$ & \\
\hline $\begin{array}{l}\text { Resectable } \\
\text { melanoma, stage } \\
\text { IIIc/IV }\end{array}$ & $\begin{array}{l}\text { Nivolumab + NY-ESO- } \\
\text { 1/gp100/Montanide }\end{array}$ & OS, RFS & NCT01176474 \\
\hline $\begin{array}{l}\text { Resectable } \\
\text { melanoma, stage } \\
\text { IIIc/IV }\end{array}$ & $\begin{array}{l}\text { Nivolumab + GVAX + } \\
\text { Cyclophosphamide }\end{array}$ & OS, DMFS ${ }^{\mathrm{a}}$ & NCT03161379a \\
\hline $\begin{array}{l}\text { Resectable } \\
\text { pancreatic cancer }\end{array}$ & $\begin{array}{l}\text { Neo/adjuvant GVAX + } \\
\text { Nivolumab }\end{array}$ & OS, RFS & NCT02451982a \\
\hline
\end{tabular}

Abbreviations: DMFS: distant metastasis free survival; gp100: glycoprotein 100; OS: overall survival; RFS: relapse free survival; GVAX: granulocyte macrophage colony-stimulating factor (GM-CSF)secreting pancreatic cancer vaccine.

a Full trial data can be retrieved at https://clinicaltrials.gov

To date, two clinical trials finished evaluating this combination therapy after resection of high-risk stage IIIc/V melanomas. In a phase II trial[94], ipilimumab was combined with a TCV after melanoma resection. The vaccine did not significantly improve the $\mathrm{T}$ cell responses, but increased the frequency of TH17 inducible cells, which was a marker of RFS. In the other trial[95], nivolumab and a multi-peptide vaccine (gp100, MART-1, and NYESO-1 with Montanide ISA 51) were provided following melanoma resection. In the treated groups, CTLA-4(+)/CD4(+), CD25(+)Treg/CD4(+), and tetramer specific CD8(+) T-cell 
population were increased. In relapse free patients, there was a trend towards lower baseline MDSCs and Tregs. Other (control) groups were however not included. New trials are in meantime scheduled to evaluate nivolumab with gp100/NY-ESO-1 TCV (NCT01176474) or nivolumab with GVAX TCV (NCT03161379) following resection of melanoma and pancreatic tumors, respectively. One trial (NCT02451982) is evaluating an interesting combination with nivolumab and GVAX before as well as after surgical resection of pancreatic cancer. Altogether, pre-clinical research convincingly provides supporting evidence for the advantages of combining TCVs with CBAs. Clinical studies have not yet yielded equally convincing data, but there appears to be reasonable interest and optimism to further explore and optimize this combination therapy. While new trials are planned, certain challenges can already be anticipated with the current experimental set-up. A noteworthy aspect is that the TCVs in most trials consist of the low immunogenic 'self-antigen' TAAs, to which tolerance have been developed during T cell education[96], in contrast to neo-antigens. Neo-antigens have been postulated as better candidates for generating stronger anti-tumor immunity, since these neo-epitopes originate from genome mutations to which these non-selfpeptides immune tolerance do not develop[97, 98]. However, a disadvantage with neoantigen vaccination is antigen identification, which is a time consuming task requiring personalized vaccine design. Furthermore, classical TAA expression could be very heterogenic among patients and generalized vaccine design is often not feasible[99]. Another current concern is the inefficient drug dosing, generation of durable immune responses, patient response rates and side effect management[20-22]. A challenge with conventional TCVs is the inefficient delivery of adjuvant and antigen to DCs, which typically hampers the generation of durable and specific anti-cancer CTL responses[100]. Adjuvants delivered in 'soluble' form also spread systemically and induce pain, erythema, swelling, flu-like symptoms and potentially fatal hematological toxicities and cytokine storms[101-104]. Similarly, CBAs are conventionally (over)dosed in the systemic circulation, thereby often IRAEs, autoimmune diseases, cytokine storms or even death. Due to these IRAEs, many immune therapies can only be combined with utmost care. The need of multiple dosing can finally rises treatment costs[105-107]. In the recent years, there is increasing interest for improving local immunotherapy with the use of nanomaterial platform based delivery systems[108]. Nanomedicine assisted local immune activation bears attractive advantages that can be integrated with cancer surgery. 


\section{NPs as promising delivery systems for optimizing TCV and CBA immunotherapy}

\subsection{Foundations of NP based research}

The term nanomedicine generally describes the application of nanotechnology in medicine. While the research field of nanomedicine is very broad, this review will be limited to the application of nanomaterials - in particular NPs - for cancer immunotherapy. NPs are colloidal structures ranging in size of 10 to $1000 \mathrm{~nm}$ and have found a broad range of application as drug delivery and imaging studies[109]. They are classified according to the material they are made up with. Polymeric NPs, lipid based NPs, micelles and gold NPs are frequently manufactured drug delivery systems. Material preference depends on various factors. Polymeric NPs manufactured with the polymer poly (lactic-co glycolic acid; PLGA) are for instance appraised for the good biocompatibility of PLGA, as PLGA hydrolysis yields the non-toxic monomers lactic acid and glycolic acid[110]. These compounds are readily metabolized with the Krebs-cycle. Liposomes are likewise popular due to their good biocompatibility. Many of the clinical approved formulations - notably for the delivery of chemotherapeutic drugs - are liposomal formulations, including Doxil, DepoCyt, DaunoXome and Onivyde[111-113]. NPs can encapsulate or be coupled with multiple compounds, including antibodies, dyes and cancer therapeutics. Such construction permits the co-delivery of multiple compounds with different functions, which could obviate the need to deliver compounds separately[114]. For instance, NPs co-delivering imaging tracking molecules (e.g. dye's, contrast agents, isotopes, etc.) and therapeutics allow in vivo tracking, which is the main emphasis of theranostics[115-117]. Another advantage of NPs is that they could improve drug pharmacokinetic (PK) properties, since NPs can release their cargo in a sustained manner. This not only increases drug bioavailability and therapeutic efficacy, it furthermore reduces unnecessary drug delivery to healthy tissue[118]. This potentially reduces the induction of off-target toxicity[119].

NPs size is a crucial parameter since size influences NP trafficking in vivo. NPs are believed to passively drain to the tumor via the hypothesized existence of the enhanced permeability retention (EPR) effect[120]. This theory is based on the leaky tumor vasculature and inefficient tumor lymphatic drainage, which permits small NPs passively draining to tumors. Caution is warranted with very small NPs $(<30 \mathrm{~nm})$, as these may be subjected to renal clearance[121]. Very large NPs, in contrast, may remain entrapped in the extra cellular matrix near the site of administration[122]. Noteworthy, these concepts are mainly based on murine studies, so it remains ambivalent whether the EPR effect exists in man[123]. Besides passive 
delivery, NPs can be conjugated with targeting moieties, in particular antibodies, in order to specifically deliver therapeutics to the targeted cell types[124, 125]. Other characteristics of NPs that could influence particle adjuvanticity include particle charge, shape, hydrophobicity and coating with surfactants. For more detailed insights on these physico-chemical properties, please consider the review article from Silva et al.[126]. In the next sessions, we will discuss the recent milestones of NP based immunotherapy, in particular for TCVs and CBAs.

3.2. NPs platform based TAA and adjuvant delivery induces effective anti-tumor immune responses

In the last years, various NPs have been formulated as multifunctional delivery system for TAAs and adjuvants (Toll-like receptor ligands; TLR-Ls) including TLR3-L (poly(I:C))[127, 128], TLR4-L (MLPA)[129-131], TLR-7/8 (R848)[132] and TLR-9L (CpG)[132-135]. These NPs platform based TCVs are sometimes referred to as 'nanovaccines' and have particularly found application in pre-clinical studies. Ranging in particular in sizes around $200 \mathrm{~nm}$ and co-delivering TLR-Ls and antigens, NPs mimic pathogens and are easily engulfed by DCs[136]. Hamdy et al.[129] showed that PLGA NPs co-encapsulating Trp2 (tyrosinase relate peptide 2) peptide and TLR4-L strongly stimulated IFN- $\gamma$ secretion at the lymph nodes and spleens, which strongly potentiated tumor containment. $\mathrm{Xu}$ et al.[135] manufactured multifunctional lipid-calcium-phosphate NPs co-delivering Trp2 peptide and TLR9-L. These NPs had superior effects on IFN- $\gamma$ production, CTL expansion and containing B16F10 tumor outgrowth, as compared to freely dosed TLR9-L and Trp2. The CTLs moreover effectively cleared distal metastasis in the lung. Ilyinskii et al.[132] also focused on immune adverse effects and demonstrated that NPs co-delivering TLR7/8-L or TLR9-L together with OVA induced strong CTL responses, without signs of systemic toxicity. In stark contrast, freely dosed adjuvants resulted in 50 to 200 folds higher serum levels IL- 6 and TNF- $\alpha$, a condition referred to as 'cytokine storm'[137]. These studies uniformly demonstrated that NP based TCVs induce more efficient DC and CTL activation and improved tumor containment, as opposed to free administration of adjuvants and antigens. These benefits are putatively attributed to antigen protection, more efficient delivery to DCs and extended release of antigen and adjuvant within DCs. These features are, among others, crucial for efficient DC maturation and the generation of strong and durable CTL responses[138]. Indeed, Silva et al.[139] demonstrated that a low burst release of antigens favors efficient DC activation. NPs facilitate the co-release of TLR-Ls and TAAs inside DCs, which could obviate the need to administer multiple compounds separately[140]. These benefits were clearly lost if burst 
release take place outside DCs, a problem with NPs releasing their cargo prematurely. This leads to comparable problems as when adjuvants and TAAs are dosed freely[141].

Since DCs are the main targets of NP based TCVs, researchers recently designed NPs with targeting moieties to specifically target DC receptors, including CD40, DEC-205, DC-SIGN and CD11c[142-146]. These receptors mediate DC uptake or activation functions. Targeting these receptors is believed to further improve DC antigen and adjuvant delivery, while limiting delivery to other tissues. DC targeting NPs demonstrated better DC and CTL activation as compared to untargeted NPs, as shown by better DC NP internalization, increased $\mathrm{T}$ cell proliferation, higher IL-12 and IFN- $\gamma$ production and more efficient tumor containment. Targeting moieties thus represent promising attributes to improve specific DC antigen and adjuvant delivery. In Fig. 2, the promises of NP based TCV therapy are represented.

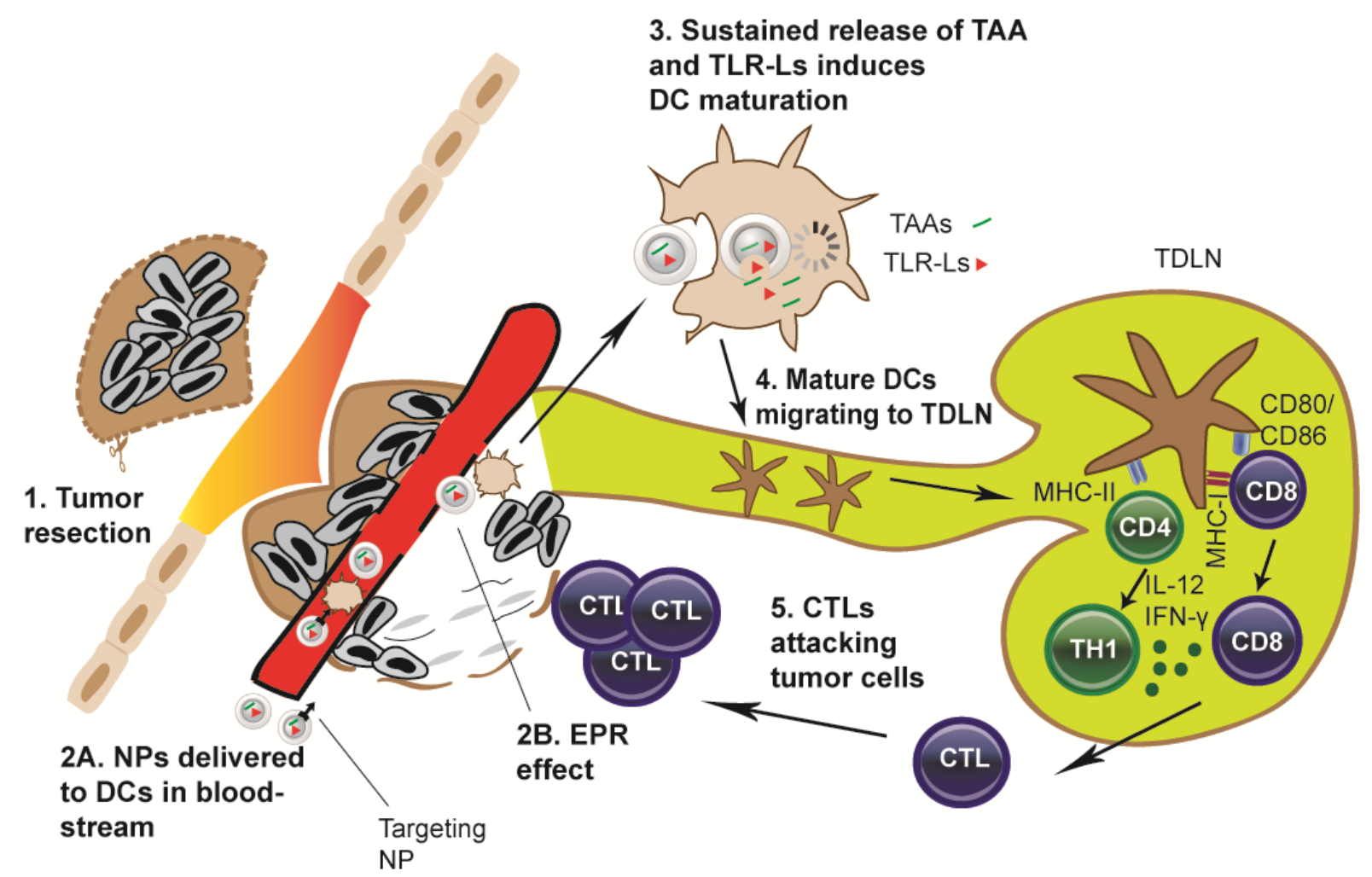

Fig. 2. Efficient DC maturation with NPs delivering TAAs and adjuvants. After tumor resection (1), vaccination with NPs could lead to DC maturation in different ways. NPs injected in bloodstream may passively reach or be actively targeted to DCs in the bloodstream (2A). NPs may furthermore passively drain to DCs residing in the tumor through the larger fenestrations in the tumor vasculature (2B). Altogether, the sustained and controlled release of TAA and TLRs initiate efficient DCs maturation (3), which migrate towards the TDLNs to efficiently prime the development of TH1 and 
CTL cells (4). Activated CTLs leave the TDLN to eliminate residual tumor cells (5). Abbreviations: CTL: cytotoxic T lymphocyte; DC: dendritic cell; EPR: enhanced permeability and retention; IFN- $\gamma$ : interferon gamma; IL-12: interleukine-12; MHC: major histocompatibility complex; TAA: tumor associated antigen; TDLN: tumor draining lymph node; TH1: T-helper 1 cell; TLR-L: Toll-like receptor ligand.

3.3. NPs mediated immune checkpoint blockade for local and sustained alleviation of immunosuppression

There is increasing optimism that local and sustained CBA delivery with slow release platforms offers promising perspectives for immune checkpoint blockade therapy[147, 148]. Simmons et al.[147] generated the GM-CSF producing cell line expressing the full-length CTLA-4 monoclonal antibody gene for cellular mediated release of anti-CTLA-4 antibody. Cellular mediated antibody delivery induced potent anti-tumor responses in mice, while furthermore reduced serum antibody concentrations. This significantly reduced the induction of systemic IRAEs. Fransen et al.[149] demonstrated that local and slow delivery of the agonistic anti-CD40 antibody with Montanide ISA 51 nearby the TDLN reduced systemic autoimmunity, as compared to systemic antibody delivery. Interestingly, when antibodies were given locally, a much lower dose sufficed for effective tumor growth containment. However, mineral oil depots bear the risk of inducing chronic inflammation-associated adverse effects[150, 151]. Lei et al.[152] encapsulated anti-CTLA-4 antibodies in functionalized mesoporous silica for achieving sustained release of anti-CTLA-4 antibodies. NPs mediated CTLA-4 blockade mediated superior effects on inhibiting tumor outgrowth, as compared to free antibodies given systemically. Rahimian et al.[153] designed polymeric microparticles (MPs) with a diameter of $12-15 \mu \mathrm{m}$ to investigate local anti-CD40 and antiCTLA-4 antibody delivery. The rationale for larger particles is that these are putatively less prone for non-specific uptake (phagocytosis) [122, 154]. The treatment was evaluated in the immune checkpoint blockade sensitive MC-38 murine colon cancer model. Incomplete Freund's Adjuvant and MP mediated CTLA-4 and CD40 blockade were equally effective in conferring MC-38 tumor growth inhibition, albeit the MP treated mice did not develop serum antibodies against the therapeutic antibodies. MP treated mice furthermore displayed no remnants of inflamed depots at the injection site. Similarly, Fransen et al.[155] evaluated anti-CD40 blockade with dextran coated MPs. Dextran is considered as an appealing biocompatible building block for slow delivery systems[156]. Dextran coated MPs loaded 
with anti-CD40 antibodies displayed slow release of anti-CD40 antibody without inducing systemic toxicity. Unfortunately, they did induce severe local inflammation without improving tumor growth inhibition. A putative explanation is that dextran contains sugar, which may have served as nutrient source for tumor cells. Polyethylene glycol (PEG) could represent an alternative for limiting non-specific uptake of NPs by phagocytes, as PEG increases the stealthness of the NPs[157, 158]. In summary, local and sustained release of CBAs could greatly improve the efficacy of immune checkpoint blocking therapies, while also reducing unnecessary spread of CBAs in the systemic circulation. Besides the reduced toxicity, it may also spare treatment costs, because of the increased CBA bioavailability and residence time (Fig. 3).

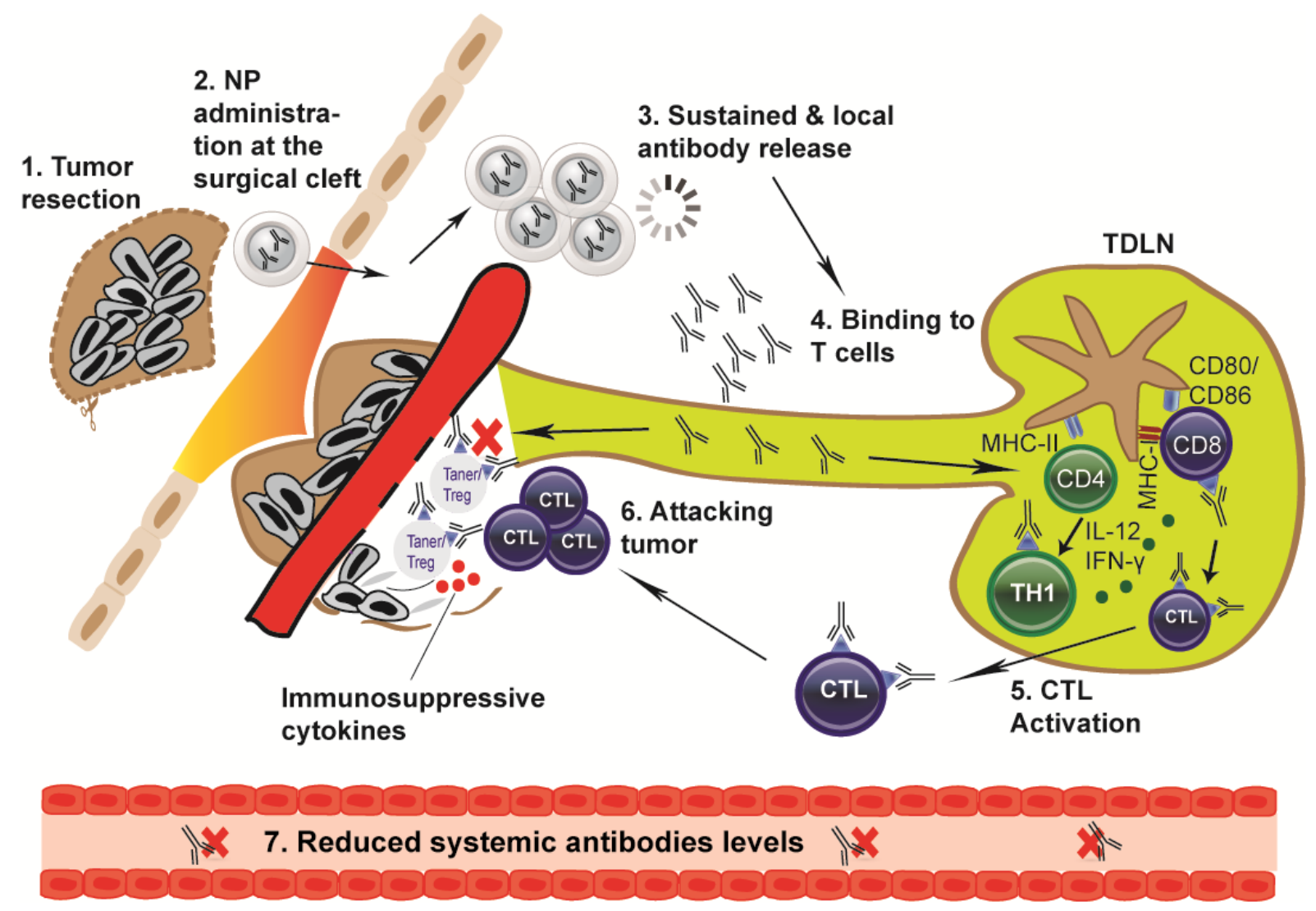

Fig. 3. NPs for sustained and local immune checkpoint blocking therapy. After tumor resection (1), the TME (left) is typically featured by the constitution of immunosuppressive Tregs/Taner cells and increased concentrations of immunosuppressive cytokines, which exert immunosuppressive effects on nearby immune cells and TDLNs. NPs administrated nearby the TME gradually release CBAs (2 and 3). Locally released CBAs then bind to inhibitory checkpoint molecules such as CTLA-4 and PD-1 (4). These alleviate immune suppression on CTLs, TH cells and stimulate their activation (5), while supposedly depleting Tregs or Taner in the TME. Activated CTLs can then effectively eliminate 
tumor cells (6). Because released locally, the antibodies are mostly retained within the TME/TDLN zone, which putatively limits the spread of antibodies in systemic circulation (7). Abbreviations: CBA: checkpoint blocking antibody; CTL: cytotoxic T lymphocyte; IFN- $\gamma$ : interferon gamma; IL-12: interleukine-12; MHC: major histocompatibility complex; Taner: anergic $\mathrm{T}$ cell; TDLN: tumor draining lymph node; TH1: T-helper 1 cell; TME: tumor microenvironment; Treg: regulatory T cell.

3.4. Post-surgical TME and TDLN as targets for local immunomodulation to inhibit postsurgical tumor outgrowth

Local and sustained immune checkpoint blockade with NPs platform based immunotherapy could keep the TME in an immunogenic state for a sustained period of time, which offers clear benefits for the generation of durable anti-tumor immune responses after surgery. For numerous reasons, TDLNs represent interesting organs of consideration when evaluating surgery with immunotherapy, as TDLNs in fact harbor the majority of relevant cells for immunotherapy[159]. As these cells tend to be immunosuppressed, it could particularly be promising to regard the (targeted) delivery of immunomodulators or checkpoint blockers to the TME to reactivate these suppressed cells. The advantage is that locally activated immune cells are capable of attacking distal metastasis, as has been shown with tumor re-challenge studies. Secondary tumors could mimic metastasis and several studies demonstrated that locally activated $\mathrm{T}$ cells could efficiently clear secondary tumors[160, 161]. It would therefore make sense to administer/target NPs in the proximity of TDLNs and TMEs zone. The sustained release of immunotherapeutics and prolonged immune activation is deemed to convert the tumor in a sustained 'protective auto-vaccine'[162]. A promising feature is that NPs could be administered more distantly from the tumor, but may still target local immune cells in the TME/TDLN. This is especially valuable for tumors or distal metastasis that are difficult to reach for surgeons. Fluorescent dyes coupled to NPs enable their tracking in vivo. Cruz et al.[163] monitored DC targeting PLGA NPs that encapsulate fluorescent and superparamagnetic iron oxide (SPIO) labeled antigen. DCs that engulfed the fluorescently and SPIO labeled NPs were traced back in the lymph nodes, which illustrates the possibility to monitor NPs and immune cell travelling in vivo.

The discussion about TDLNs as immune organs could raise interesting questions for surgeons, as they typically consider TDLNs as cancerous tissues. Khong et al.[164] addressed this dubious question by evaluating the agonistic anti-CD40 antibody following surgical resection of subcutaneous $\mathrm{AB} 1-\mathrm{HA}$ mesothelioma tumors in $\mathrm{BALB} / \mathrm{c}$ mice. Recurrence was 
mimicked by injecting tumor cells in the post-surgical wound. Agonistic anti-CD40 antibody stimulated DC activation and facilitated tumor specific CTL priming. Interestingly, TDLN resection did not abrogate anti-CD40 therapy efficacy. This suggests that, at least for the efficacy of anti-CD40 therapy, TDLNs were dispensable. In their subsequent study[165], anti-CD40 therapy together with TLR7 ligand imiquimod were evaluated as post-surgical immunotherapy with the same tumor model, albeit without TDLN resection. Post-surgical anti-CD40 + imiquimod therapy effectively facilitated tumor growth inhibition and expanded TILs number in the TDLN and tumor. A recent study further underscored the promises of local and sustained immune activation following surgery with the use of hydrogels scaffolds. Hydrogel scaffolds are another class of nanomaterial that could extend immunotherapeutic drug release. Engraftment of hydrogels loaded with different compounds, including TLR7/8, anti-PD-1 or anti-CTLA-4 after surgery greatly increased the numbers of DCs, NK cells and $\mathrm{T}$ cells, while also induced production of type I interferons. This indicates the conversion of an immunosuppressive TME into one that favors TH1 anti-tumor immunity. In line with this, the local treatment reduced development of post-surgical metastasis in mice carrying 4T1 tumors [166]. These benefits were neither observed in mice receiving the same treatment in PBS nor in those receiving the treatment systemically. While local and sustained drug release was crucial, the authors also speculated on the timing of the immunotherapy, as hydrogel scaffold were implanted directly after tumor resection (peri-operative therapy). The advantage of peri-operative immunotherapy is that the tumor is directly accessible for immunotherapeutics. Furthermore, peri-operative immunotherapy may directly counteract surgical stress induced immunosuppression. In contrast, the study from Liu et al.[167] evaluated immunotherapy before tumor resection (neo-adjuvant therapy). The authors demonstrated that the combined neo-adjuvant anti-PD-1 and anti-4-1BB therapy strongly prevents post-surgical recurrence in $4 \mathrm{~T} 1$ tumors. In contrast, mice receiving the therapy few days later after surgery developed more metastasis and larger tumors. A rationale for neoadjuvant is that the tumor mass is still present, which serves as a source of TAAs for T cells. Also, immunity has not been affected yet by surgery. More studies are required in order to find the optimal dosing moments of immunotherapy with respect to surgery.

\section{Future perspective of combinational NP based immunotherapy}

When evaluating immunotherapy in combination with surgery, it is important to consider the complex interplay between the immune system, tumor pathophysiology and the effects of 
surgery on the TME. Until now, these concepts have only been partially addressed in (pre)clinical studies, however there is increasing awareness that surgery could impact immunotherapy. The difficulty of eliminating recurring cancers with conventional TCVs calls for the exploration of stronger combination immunotherapeutic treatment regimens that target the anti-tumor immune response at multiple levels. Different strategies could be envisaged, such as reducing the amount of Tregs and TAMs, depleting immunosuppressive cytokines and stimulating immune pathways that favor anti-tumor immunity[168]. A desired outcome is the generation of durable high affinity anti-tumor immune responses that effectively clear the tumor, while exerting minimal cytotoxicity. This goal is putatively attainable by creating, or re-establishing a TME that favors the generation of anti-tumor immune responses, without affecting wound healing. Whilst combined immunotherapy represents a promising avenue of research, certain aspects need to be regarded carefully. Uncontrolled immune activation could strongly limit the evaluation of potentially strong combination therapies. Furthermore, combination treatments may interfere with each other, which should be avoided by carefully timing the administration moment of the different modalities. Particularly the type of CBA could play an important role, since they exert their (predominant) effects at different phases within the immune cycle. Rather than giving all modalities at once, it is recommended to give the different modalities in sequence, repeat the treatment by multiple drug dosing and treat at different locations. To demonstrate, anti-CTLA-4 is expected to be most efficient at the moment when $\mathrm{T}$ cells received a strong TCR signal from potent vaccines, and it is suggested to be more efficient at the time a second (booster) vaccine is given[169].

In this review, we addressed how recent investments in nanomedicine based immunotherapy research clearly sparked the interests of NPs as delivery system for cancer immunotherapy. Alongside the growing interest for manufacturing and optimizing NPs for TCV and CBA based immunotherapy, combined NP based immune checkpoint blockade with TCVs could emerge as a future treatment strategy for more effective post-surgical TME immunomodulation. This is putatively a pivotal step for the treatment of post-surgical recurrences, as depicted in Fig. 4. 


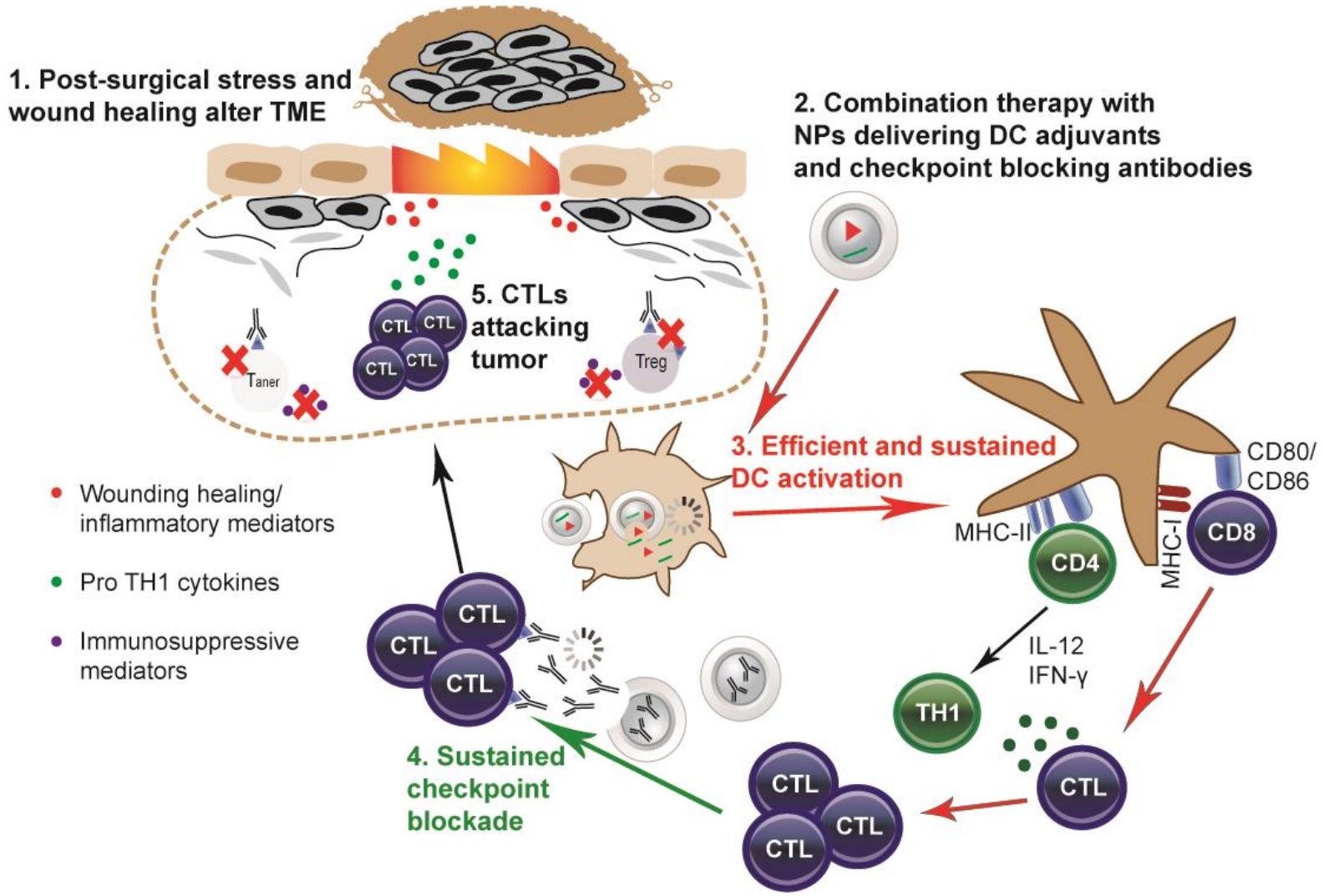

Fig. 4. The promises of synergistic NP based immunotherapy with TCVs and CBAs. Surgery triggers stress and tends to lead to aberrant alteration of the TME (1). A more effective treatment approach is putatively realized with combination immunotherapy with NPs inducing DC maturation and NPs delivering CBAs, which could mediate synergistic effects on tumor elimination (2). Sustained TAA and TLR release leads on one hand to efficient DC maturation (3; pathway shown with red arrows) and mature DCs efficiently prime CTL development. On the other hand, NPs releasing CBAs can alleviate immunosuppression on immune cells (4; pathway shown with green arrow). Proper dosing schedules and repeated dosing could further improve therapeutic outcome. The sustained bioavailability of immunotherapeutics prolong immune cell activation, which is deemed to convert the immunosuppressive post-surgical TME into one that favors CTL mediated anti-tumor immunity (5). Abbreviations: CBA: checkpoint blocking antibody; CTL: cytotoxic T lymphocyte; DC: dendritic cell; IFN- $\gamma$ : interferon gamma; IL-12: interleukine-12; MHC: major histocompatibility complex; Taner: anergic T cells; TH1: T-helper 1 cell; Treg: regulatory T cells

Several studies are already under way to explore combination immunotherapies with the aid of nanomedicine. Ali et al.[170] combined PLGA NP GVAX vaccine with CTLA-4 and PD1 blockade, which efficiently facilitated the regression of B16 melanoma tumor in mice, even without vaccine boosting. Particularly CTLA-4 blockade strongly increased CTL activity in the TDLN and at the site of vaccination, while PD-1 blockade alone increased CTL activity 
in the tumor only. Chen et al.[171] assessed the synergism between CTLA-4 blockade and PLGA NPs co-delivering imiquimod with indocyanine green (photothermal compound). The NPs were used for near infrared (NIR) laser mediated photothermal therapy of primary tumors, thereby inducing immunogenic cell death and the release of TAAs. The imiquimod release in the dying tumor cells served as an endogenous vaccine, which strongly synergized with CTLA-4 blocking antibodies to clear distal metastasis. CTLA-4 blockade combined with NPs was furthermore evaluated as post-surgical therapy. The combination therapy effectively cleared primary tumors and distal metastasis, while neither mono-therapy with CTLA-4 blockade nor NP alone facilitated tumor growth inhibition. NP based combination treatments that target other (comparable) immunostimulatory and immunosuppressive pathways in the TME are also under development. Xu et al.[172] evaluated a combined NP immunotherapy, with one set of NP (vaccine NP) delivering Trp2 peptide and TLR9-L CpG to stimulate DCs and another set of lipid-polymer hybrid NPs delivering siRNA to suppress TGF- $\beta$ expression in the TME. The combination therapy facilitated significant inhibition of tumor growth compared to mice receiving the NP vaccine only. Park et al.[173] formulated a combination therapy within one NP delivery system with IL-2 adjuvant and TGF- $\beta$ inhibitor using nanolipogel NPs, which effectively contained outgrowth of B16 melanoma tumors. Options remain open to encapsulate various other types of immunotherapeutics, ranging from adjuvants, siRNAs, immunomodulatory antibodies etc. Regarding these developments, it is conceivable that NP based immunotherapy will find application soon in the clinic. One PLGA nanovaccine formulation (WDvax) is already being evaluated in a phase I trial for melanoma (NCT01753089).

\section{Conclusion}

Surgery could induce a general state of immunosuppression with the post-surgical TME often being manifested by profound cellular and cytokine changes. These changes do not favor anti-tumor immunity, whilst also promoting tumor cell outgrowth. More durable response rates are likely attainable by strategically combining immunotherapies that change the postsurgical TME into one that promotes anti-tumor immunity. Versatile combined NP based immunotherapies with TCVs and CBAs may serve well for post-surgical TME immunomodulation and yielding better response rates in patients. 


\section{Grant support}

This work was supported by project grants from the European Commission H2020-MSCARISE (644373 - PRISAR), H2020-MSCA-RISE (777682 - CANCER) and MSCA-ITN2015-ETN (675743 - ISPIC). This work was also financially supported by the VIDI personal grant (project number 723.012.110) L.J.C.

\section{Declaration of interest}

AC is affiliated to Percuros B.V. as a founder. DK is affiliated to JeNaCell $\mathrm{GmbH}$ as a founder.

\section{Acknowledgment}

Conception of idea: CK Chung, CG Da Silva and LJ Cruz; CK Chung collected literature, drafted the first version and made the graphical illustrations. CG Da Silva made revisions on the first draft. A Chan, D Kralisch, F Ossendorp and LJ Cruz revised the manuscript and LJ Cruz made the final additions. All authors agreed on the final content. 


\section{References}

[1] R.L. Siegel, K.D. Miller, A. Jemal, Cancer statistics, 2016, CA: a cancer journal for clinicians 66(1) (2016) 7-30.

[2] H. Uramoto, F. Tanaka, Recurrence after surgery in patients with NSCLC, Translational lung cancer research 3(4) (2014) 242-9.

[3] A.N. Tavare, N.J. Perry, L.L. Benzonana, M. Takata, D. Ma, Cancer recurrence after surgery: direct and indirect effects of anesthetic agents, International journal of cancer. Journal international du cancer 130(6) (2012) 1237-50.

[4] B.A. Chabner, T.G. Roberts, Jr., Timeline: Chemotherapy and the war on cancer, Nature reviews. Cancer 5(1) (2005) 65-72.

[5] S. Baker, M. Dahele, F.J. Lagerwaard, S. Senan, A critical review of recent developments in radiotherapy for non-small cell lung cancer, Radiation oncology 11(1) (2016) 115.

[6] G. Parmiani, C. Castelli, P. Dalerba, R. Mortarini, L. Rivoltini, F.M. Marincola, A. Anichini, Cancer immunotherapy with peptide-based vaccines: what have we achieved? Where are we going?, Journal of the National Cancer Institute 94(11) (2002) 805-18. [7] D.M. Pardoll, The blockade of immune checkpoints in cancer immunotherapy, Nature reviews. Cancer 12(4) (2012) 252-64.

[8] C.J. Melief, T. van Hall, R. Arens, F. Ossendorp, S.H. van der Burg, Therapeutic cancer vaccines, The Journal of clinical investigation 125(9) (2015) 3401-12.

[9] R. Demicheli, M.W. Retsky, W.J. Hrushesky, M. Baum, I.D. Gukas, The effects of surgery on tumor growth: a century of investigations, Annals of oncology : official journal of the European Society for Medical Oncology 19(11) (2008) 1821-8.

[10] K. Shao, S. Singha, X. Clemente-Casares, S. Tsai, Y. Yang, P. Santamaria, Nanoparticle-based immunotherapy for cancer, ACS nano 9(1) (2015) 16-30.

[11] Z. Zhang, Y. Guo, S.S. Feng, Nanoimmunotherapy: application of nanotechnology for sustained and targeted delivery of antigens to dendritic cells, Nanomedicine 7(1) (2012) 1-4. [12] C.G. Da Silva, F. Rueda, C.W. Lowik, F. Ossendorp, L.J. Cruz, Combinatorial prospects of nano-targeted chemoimmunotherapy, Biomaterials 83 (2016) 308-20.

[13] F.M. Burnet, Immunological aspects of malignant disease, Lancet 1(7501) (1967) 11714.

[14] J.B. Swann, M.J. Smyth, Immune surveillance of tumors, The Journal of clinical investigation 117(5) (2007) 1137-46.

[15] R. Kim, M. Emi, K. Tanabe, Cancer immunoediting from immune surveillance to immune escape, Immunology 121(1) (2007) 1-14.

[16] O.P. Joffre, E. Segura, A. Savina, S. Amigorena, Cross-presentation by dendritic cells, Nature reviews. Immunology 12(8) (2012) 557-69.

[17] G.E. Kaiko, J.C. Horvat, K.W. Beagley, P.M. Hansbro, Immunological decision-making: how does the immune system decide to mount a helper T-cell response?, Immunology 123(3) (2008) 326-38.

[18] M.B. Lappin, J.D. Campbell, The Th1-Th2 classification of cellular immune responses: concepts, current thinking and applications in haematological malignancy, Blood reviews 14(4) (2000) 228-39.

[19] C. Guo, M.H. Manjili, J.R. Subjeck, D. Sarkar, P.B. Fisher, X.Y. Wang, Therapeutic cancer vaccines: past, present, and future, Advances in cancer research 119 (2013) 421-75. [20] I. Melero, G. Gaudernack, W. Gerritsen, C. Huber, G. Parmiani, S. Scholl, N. Thatcher, J. Wagstaff, C. Zielinski, I. Faulkner, H. Mellstedt, Therapeutic vaccines for cancer: an overview of clinical trials, Nature reviews. Clinical oncology 11(9) (2014) 509-24. [21] I. Mellman, G. Coukos, G. Dranoff, Cancer immunotherapy comes of age, Nature 480(7378) (2011) 480-9. 
[22] L. Buonaguro, A. Petrizzo, M.L. Tornesello, F.M. Buonaguro, Translating tumor antigens into cancer vaccines, Clinical and vaccine immunology : CVI 18(1) (2011) 23-34. [23] R. Soiffer, F.S. Hodi, F. Haluska, K. Jung, S. Gillessen, S. Singer, K. Tanabe, R. Duda, S. Mentzer, M. Jaklitsch, R. Bueno, S. Clift, S. Hardy, D. Neuberg, R. Mulligan, I. Webb, M. Mihm, G. Dranoff, Vaccination with irradiated, autologous melanoma cells engineered to secrete granulocyte-macrophage colony-stimulating factor by adenoviral-mediated gene transfer augments antitumor immunity in patients with metastatic melanoma, Journal of clinical oncology : official journal of the American Society of Clinical Oncology 21(17) (2003) 3343-50.

[24] R. Soiffer, T. Lynch, M. Mihm, K. Jung, C. Rhuda, J.C. Schmollinger, F.S. Hodi, L. Liebster, P. Lam, S. Mentzer, S. Singer, K.K. Tanabe, A.B. Cosimi, R. Duda, A. Sober, A. Bhan, J. Daley, D. Neuberg, G. Parry, J. Rokovich, L. Richards, J. Drayer, A. Berns, S. Clift, L.K. Cohen, R.C. Mulligan, G. Dranoff, Vaccination with irradiated autologous melanoma cells engineered to secrete human granulocyte-macrophage colony-stimulating factor generates potent antitumor immunity in patients with metastatic melanoma, Proceedings of the National Academy of Sciences of the United States of America 95(22) (1998) 13141-6. [25] G. Dranoff, R. Soiffer, T. Lynch, M. Mihm, K. Jung, K. Kolesar, L. Liebster, P. Lam, R. Duda, S. Mentzer, S. Singer, K. Tanabe, R. Johnson, A. Sober, A. Bhan, S. Clift, L. Cohen, G. Parry, J. Rokovich, L. Richards, J. Drayer, A. Berns, R.C. Mulligan, A phase I study of vaccination with autologous, irradiated melanoma cells engineered to secrete human granulocyte-macrophage colony stimulating factor, Human gene therapy 8(1) (1997) 111-23. [26] C.A. Uyl-de Groot, J.B. Vermorken, M.G. Hanna, Jr., P. Verboom, M.T. Groot, G.J. Bonsel, C.J. Meijer, H.M. Pinedo, Immunotherapy with autologous tumor cell-BCG vaccine in patients with colon cancer: a prospective study of medical and economic benefits, Vaccine 23(17-18) (2005) 2379-87.

[27] X. Tai, F. Van Laethem, L. Pobezinsky, T. Guinter, S.O. Sharrow, A. Adams, L. Granger, M. Kruhlak, T. Lindsten, C.B. Thompson, L. Feigenbaum, A. Singer, Basis of CTLA-4 function in regulatory and conventional CD4(+) T cells, Blood 119(22) (2012) 5155-63.

[28] K. Wing, Y. Onishi, P. Prieto-Martin, T. Yamaguchi, M. Miyara, Z. Fehervari, T. Nomura, S. Sakaguchi, CTLA-4 control over Foxp3+ regulatory T cell function, Science 322(5899) (2008) 271-5.

[29] M.F. Krummel, J.P. Allison, Pillars article: CD28 and CTLA-4 have opposing effects on the response of T cells to stimulation. The journal of experimental medicine. 1995. 182: 459465, Journal of immunology 187(7) (2011) 3459-65.

[30] T.F. Gajewski, H. Schreiber, Y.X. Fu, Innate and adaptive immune cells in the tumor microenvironment, Nature immunology 14(10) (2013) 1014-22.

[31] M. Santarpia, N. Karachaliou, Tumor immune microenvironment characterization and response to anti-PD-1 therapy, Cancer biology \& medicine 12(2) (2015) 74-8.

[32] J. He, Y. Hu, M. Hu, B. Li, Development of PD-1/PD-L1 Pathway in Tumor Immune Microenvironment and Treatment for Non-Small Cell Lung Cancer, Scientific reports 5 (2015) 13110.

[33] A.J. Korman, K.S. Peggs, J.P. Allison, Checkpoint blockade in cancer immunotherapy, Advances in immunology 90 (2006) 297-339.

[34] F.S. Hodi, S.J. O'Day, D.F. McDermott, R.W. Weber, J.A. Sosman, J.B. Haanen, R. Gonzalez, C. Robert, D. Schadendorf, J.C. Hassel, W. Akerley, A.J. van den Eertwegh, J. Lutzky, P. Lorigan, J.M. Vaubel, G.P. Linette, D. Hogg, C.H. Ottensmeier, C. Lebbe, C. Peschel, I. Quirt, J.I. Clark, J.D. Wolchok, J.S. Weber, J. Tian, M.J. Yellin, G.M. Nichol, A. Hoos, W.J. Urba, Improved survival with ipilimumab in patients with metastatic melanoma, The New England journal of medicine 363(8) (2010) 711-23. 
[35] J.R. Brahmer, C.G. Drake, I. Wollner, J.D. Powderly, J. Picus, W.H. Sharfman, E. Stankevich, A. Pons, T.M. Salay, T.L. McMiller, M.M. Gilson, C. Wang, M. Selby, J.M. Taube, R. Anders, L. Chen, A.J. Korman, D.M. Pardoll, I. Lowy, S.L. Topalian, Phase I study of single-agent anti-programmed death-1 (MDX-1106) in refractory solid tumors: safety, clinical activity, pharmacodynamics, and immunologic correlates, Journal of clinical oncology : official journal of the American Society of Clinical Oncology 28(19) (2010) 316775.

[36] S.L. Topalian, M. Sznol, D.F. McDermott, H.M. Kluger, R.D. Carvajal, W.H. Sharfman, J.R. Brahmer, D.P. Lawrence, M.B. Atkins, J.D. Powderly, P.D. Leming, E.J. Lipson, I. Puzanov, D.C. Smith, J.M. Taube, J.M. Wigginton, G.D. Kollia, A. Gupta, D.M. Pardoll, J.A. Sosman, F.S. Hodi, Survival, durable tumor remission, and long-term safety in patients with advanced melanoma receiving nivolumab, Journal of clinical oncology : official journal of the American Society of Clinical Oncology 32(10) (2014) 1020-30.

[37] J.D. Wolchok, H. Kluger, M.K. Callahan, M.A. Postow, N.A. Rizvi, A.M. Lesokhin, N.H. Segal, C.E. Ariyan, R.A. Gordon, K. Reed, M.M. Burke, A. Caldwell, S.A. Kronenberg, B.U. Agunwamba, X. Zhang, I. Lowy, H.D. Inzunza, W. Feely, C.E. Horak, Q. Hong, A.J. Korman, J.M. Wigginton, A. Gupta, M. Sznol, Nivolumab plus ipilimumab in advanced melanoma, The New England journal of medicine 369(2) (2013) 122-33.

[38] A.M. Eggermont, V. Chiarion-Sileni, J.J. Grob, R. Dummer, J.D. Wolchok, H. Schmidt, O. Hamid, C. Robert, P.A. Ascierto, J.M. Richards, C. Lebbe, V. Ferraresi, M. Smylie, J.S. Weber, M. Maio, C. Konto, A. Hoos, V. de Pril, R.K. Gurunath, G. de Schaetzen, S. Suciu, A. Testori, Adjuvant ipilimumab versus placebo after complete resection of high-risk stage III melanoma (EORTC 18071): a randomised, double-blind, phase 3 trial, The Lancet. Oncology 16(5) (2015) 522-30.

[39] A.M. Eggermont, V. Chiarion-Sileni, J.J. Grob, R. Dummer, J.D. Wolchok, H. Schmidt, O. Hamid, C. Robert, P.A. Ascierto, J.M. Richards, C. Lebbe, V. Ferraresi, M. Smylie, J.S. Weber, M. Maio, L. Bastholt, L. Mortier, L. Thomas, S. Tahir, A. Hauschild, J.C. Hassel, F.S. Hodi, C. Taitt, V. de Pril, G. de Schaetzen, S. Suciu, A. Testori, Prolonged Survival in Stage III Melanoma with Ipilimumab Adjuvant Therapy, The New England journal of medicine 375(19) (2016) 1845-1855.

[40] R. Hajkova, M. Indrova, T. Jandlova, J. Bubenik, M. Reinis, Interleukin 2 gene therapy of surgical minimal residual tumour disease: characterization of cytolytic effector cells from tumour progressors and regressors, Folia biologica 45(6) (1999) 227-31.

[41] M. Indrova, R. Mikyskova, T. Jandlova, V. Vonka, J. Bubenik, J. Bieblova, Adjuvant cytokine treatment of minimal residual disease after surgical therapy in mice carrying HPV16-associated tumours: cytolytic activity of spleen cells from tumour regressors, Folia biologica 49(6) (2003) 217-22.

[42] E.C. Hsueh, R. Essner, L.J. Foshag, D.W. Ollila, G. Gammon, S.J. O'Day, P.D. Boasberg, S.L. Stern, X. Ye, D.L. Morton, Prolonged survival after complete resection of disseminated melanoma and active immunotherapy with a therapeutic cancer vaccine, Journal of clinical oncology : official journal of the American Society of Clinical Oncology 20(23) (2002) 4549-54.

[43] D.L. Morton, Immune response to postsurgical adjuvant active immunotherapy with Canvaxin polyvalent cancer vaccine: correlations with clinical course of patients with metastatic melanoma, Developments in biologicals 116 (2004) 209-17; discussion 229-36. [44] D.L. Morton, E.C. Hsueh, R. Essner, L.J. Foshag, S.J. O'Day, A. Bilchik, R.K. Gupta, D.S. Hoon, M. Ravindranath, J.A. Nizze, G. Gammon, L.A. Wanek, H.J. Wang, R.M. Elashoff, Prolonged survival of patients receiving active immunotherapy with Canvaxin therapeutic polyvalent vaccine after complete resection of melanoma metastatic to regional lymph nodes, Annals of surgery 236(4) (2002) 438-48; discussion 448-9. 
[45] Z.C. Tucker, B.A. Laguna, E. Moon, S. Singhal, Adjuvant immunotherapy for non-small cell lung cancer, Cancer treatment reviews 38(6) (2012) 650-61.

[46] J.M. Kirkwood, J. Manola, J. Ibrahim, V. Sondak, M.S. Ernstoff, U. Rao, G. Eastern Cooperative Oncology, A pooled analysis of eastern cooperative oncology group and intergroup trials of adjuvant high-dose interferon for melanoma, Clinical cancer research : an official journal of the American Association for Cancer Research 10(5) (2004) 1670-7. [47] S. Mocellin, C.R. Rossi, M. Lise, F.M. Marincola, Adjuvant immunotherapy for solid tumors: from promise to clinical application, Cancer immunology, immunotherapy : CII 51(11-12) (2002) 583-95.

[48] J.D. Predina, B. Judy, Z.G. Fridlender, L.A. Aliperti, B. Madajewski, V. Kapoor, G. Cheng, J. Quatromoni, O. Okusanya, S. Singhal, A positive-margin resection model recreates the postsurgical tumor microenvironment and is a reliable model for adjuvant therapy evaluation, Cancer biology \& therapy 13(9) (2012) 745-55.

[49] A.K. Olsson, A. Dimberg, J. Kreuger, L. Claesson-Welsh, VEGF receptor signalling - in control of vascular function, Nature reviews. Molecular cell biology 7(5) (2006) 359-71. [50] N. Ferrara, VEGF and the quest for tumour angiogenesis factors, Nature reviews. Cancer 2(10) (2002) 795-803.

[51] P. Carmeliet, Angiogenesis in life, disease and medicine, Nature 438(7070) (2005) 9326.

[52] J.G. Hiller, N.J. Perry, G. Poulogiannis, B. Riedel, E.K. Sloan, Perioperative events influence cancer recurrence risk after surgery, Nature reviews. Clinical oncology 15(4) (2018) 205-218.

[53] R. Palacios, I. Sugawara, Hydrocortisone abrogates proliferation of T cells in autologous mixed lymphocyte reaction by rendering the interleukin-2 Producer T cells unresponsive to interleukin-1 and unable to synthesize the T-cell growth factor, Scandinavian journal of immunology 15(1) (1982) 25-31.

[54] M.G. Belvisi, Regulation of inflammatory cell function by corticosteroids, Proceedings of the American Thoracic Society 1(3) (2004) 207-14.

[55] J.P. Duignan, P.B. Collins, A.H. Johnson, D. Bouchier-Hayes, The association of impaired neutrophil chemotaxis with postoperative surgical sepsis, The British journal of surgery 73(3) (1986) 238-40.

[56] Y. Tabuchi, S. Shinka, H. Ishida, The effects of anesthesia and surgery on count and function of neutrophils, Journal of anesthesia 3(2) (1989) 123-31.

[57] X. Gan, L. Zhang, G.F. Solomon, B. Bonavida, Mechanism of norepinephrine-mediated inhibition of human NK cytotoxic functions: inhibition of cytokine secretion, target binding, and programming for cytotoxicity, Brain, behavior, and immunity 16(3) (2002) 227-46.

[58] K. Hellstrand, S. Hermodsson, An immunopharmacological analysis of adrenalineinduced suppression of human natural killer cell cytotoxicity, International archives of allergy and applied immunology 89(4) (1989) 334-41.

[59] J.D. Spahn, L.P. Landwehr, S. Nimmagadda, W. Surs, D.Y. Leung, S.J. Szefler, Effects of glucocorticoids on lymphocyte activation in patients with steroid-sensitive and steroidresistant asthma, The Journal of allergy and clinical immunology 98(6 Pt 1) (1996) 1073-9. [60] J. Hamid, J. Bancewicz, R. Brown, C. Ward, M.H. Irving, W.L. Ford, The significance of changes in blood lymphocyte populations following surgical operations, Clinical and experimental immunology 56(1) (1984) 49-57.

[61] K. Ogawa, M. Hirai, T. Katsube, M. Murayama, K. Hamaguchi, T. Shimakawa, Y. Naritake, T. Hosokawa, T. Kajiwara, Suppression of cellular immunity by surgical stress, Surgery 127(3) (2000) 329-36. 
[62] R. Tian, G. Hou, D. Li, T.F. Yuan, A possible change process of inflammatory cytokines in the prolonged chronic stress and its ultimate implications for health, TheScientificWorldJournal 2014 (2014) 780616.

[63] R. Brattsand, M. Linden, Cytokine modulation by glucocorticoids: mechanisms and actions in cellular studies, Alimentary pharmacology \& therapeutics 10 Suppl 2 (1996) 8190; discussion 91-2.

[64] P.J. Barnes, Anti-inflammatory actions of glucocorticoids: molecular mechanisms, Clinical science 94(6) (1998) 557-72.

[65] I. Kelbel, M. Weiss, Anaesthetics and immune function, Current opinion in anaesthesiology 14(6) (2001) 685-91.

[66] B.A. Fuchs, S.B. Pruett, Morphine induces apoptosis in murine thymocytes in vivo but not in vitro: involvement of both opiate and glucocorticoid receptors, The Journal of pharmacology and experimental therapeutics 266(1) (1993) 417-23.

[67] B. Beilin, Y. Shavit, J. Hart, B. Mordashov, S. Cohn, I. Notti, H. Bessler, Effects of anesthesia based on large versus small doses of fentanyl on natural killer cell cytotoxicity in the perioperative period, Anesthesia and analgesia 82(3) (1996) 492-7.

[68] I.Z. Yardeni, B. Beilin, E. Mayburd, Y. Alcalay, H. Bessler, Relationship between fentanyl dosage and immune function in the postoperative period, Journal of opioid management 4(1) (2008) 27-33.

[69] J.L. Roh, M.W. Sung, S.W. Park, D.S. Heo, D.W. Lee, K.H. Kim, Celecoxib can prevent tumor growth and distant metastasis in postoperative setting, Cancer research 64(9) (2004) 3230-5.

[70] G.S. Schultz, M. White, R. Mitchell, G. Brown, J. Lynch, D.R. Twardzik, G.J. Todaro, Epithelial wound healing enhanced by transforming growth factor-alpha and vaccinia growth factor, Science 235(4786) (1987) 350-2.

[71] G. Shakhar, S. Ben-Eliyahu, Potential prophylactic measures against postoperative immunosuppression: could they reduce recurrence rates in oncological patients?, Annals of surgical oncology 10(8) (2003) 972-92.

[72] M.H. Manjili, S.E. Butler, Role of Tregs in Cancer Dormancy or Recurrence, Immunological investigations 45(8) (2016) 759-766.

[73] J. Predina, E. Eruslanov, B. Judy, V. Kapoor, G. Cheng, L.C. Wang, J. Sun, E.K. Moon, Z.G. Fridlender, S. Albelda, S. Singhal, Changes in the local tumor microenvironment in recurrent cancers may explain the failure of vaccines after surgery, Proceedings of the National Academy of Sciences of the United States of America 110(5) (2013) E415-24. [74] C. Wang, W. Sun, Y. Ye, Q. Hu, H.N. Bomba, Z. Gu, In situ activation of platelets with checkpoint inhibitors for post-surgical cancer immunotherapy, Nature Biomedical Engineering 1 (2017) 0011.

[75] A.A. Hurwitz, T.F. Yu, D.R. Leach, J.P. Allison, CTLA-4 blockade synergizes with tumor-derived granulocyte-macrophage colony-stimulating factor for treatment of an experimental mammary carcinoma, Proceedings of the National Academy of Sciences of the United States of America 95(17) (1998) 10067-71.

[76] A. van Elsas, A.A. Hurwitz, J.P. Allison, Combination immunotherapy of B16 melanoma using anti-cytotoxic T lymphocyte-associated antigen 4 (CTLA-4) and granulocyte/macrophage colony-stimulating factor (GM-CSF)-producing vaccines induces rejection of subcutaneous and metastatic tumors accompanied by autoimmune depigmentation, The Journal of experimental medicine 190(3) (1999) 355-66.

[77] A.A. Hurwitz, B.A. Foster, E.D. Kwon, T. Truong, E.M. Choi, N.M. Greenberg, M.B. Burg, J.P. Allison, Combination immunotherapy of primary prostate cancer in a transgenic mouse model using CTLA-4 blockade, Cancer research 60(9) (2000) 2444-8. 
[78] L.I. Dos Santos, B. Galvao-Filho, P.C. de Faria, C. Junqueira, M.S. Dutra, S.M. Teixeira, M.M. Rodrigues, G. Ritter, O. Bannard, D.T. Fearon, L.R. Antonelli, R.T. Gazzinelli, Blockade of CTLA-4 promotes the development of effector CD8+ T lymphocytes and the therapeutic effect of vaccination with an attenuated protozoan expressing NY-ESO-1, Cancer immunology, immunotherapy : CII 64(3) (2015) 311-23.

[79] R.P. Sutmuller, L.M. van Duivenvoorde, A. van Elsas, T.N. Schumacher, M.E. Wildenberg, J.P. Allison, R.E. Toes, R. Offringa, C.J. Melief, Synergism of cytotoxic T lymphocyte-associated antigen 4 blockade and depletion of CD25(+) regulatory T cells in antitumor therapy reveals alternative pathways for suppression of autoreactive cytotoxic $\mathrm{T}$ lymphocyte responses, The Journal of experimental medicine 194(6) (2001) 823-32.

[80] T.R. Simpson, F. Li, W. Montalvo-Ortiz, M.A. Sepulveda, K. Bergerhoff, F. Arce, C. Roddie, J.Y. Henry, H. Yagita, J.D. Wolchok, K.S. Peggs, J.V. Ravetch, J.P. Allison, S.A. Quezada, Fc-dependent depletion of tumor-infiltrating regulatory $\mathrm{T}$ cells co-defines the efficacy of anti-CTLA-4 therapy against melanoma, The Journal of experimental medicine 210(9) (2013) 1695-710.

[81] M.A. Curran, W. Montalvo, H. Yagita, J.P. Allison, PD-1 and CTLA-4 combination blockade expands infiltrating $\mathrm{T}$ cells and reduces regulatory $\mathrm{T}$ and myeloid cells within $\mathrm{B} 16$ melanoma tumors, Proceedings of the National Academy of Sciences of the United States of America 107(9) (2010) 4275-80.

[82] K.S. Peggs, S.A. Quezada, C.A. Chambers, A.J. Korman, J.P. Allison, Blockade of CTLA-4 on both effector and regulatory T cell compartments contributes to the antitumor activity of anti-CTLA-4 antibodies, The Journal of experimental medicine 206(8) (2009) 1717-25.

[83] B.T. Rekoske, H.A. Smith, B.M. Olson, B.B. Maricque, D.G. McNeel, PD-1 or PD-L1 Blockade Restores Antitumor Efficacy Following SSX2 Epitope-Modified DNA Vaccine Immunization, Cancer immunology research 3(8) (2015) 946-55.

[84] S. Chen, L.F. Lee, T.S. Fisher, B. Jessen, M. Elliott, W. Evering, K. Logronio, G.H. Tu, K. Tsaparikos, X. Li, H. Wang, C. Ying, M. Xiong, T. VanArsdale, J.C. Lin, Combination of 4-1BB agonist and PD-1 antagonist promotes antitumor effector/memory CD8 T cells in a poorly immunogenic tumor model, Cancer immunology research 3(2) (2015) 149-60.

[85] Y. Sawada, T. Yoshikawa, M. Shimomura, T. Iwama, I. Endo, T. Nakatsura, Programmed death-1 blockade enhances the antitumor effects of peptide vaccine-induced peptide-specific cytotoxic T lymphocytes, International journal of oncology 46(1) (2015) 28 36.

[86] K.C. Soares, A.A. Rucki, A.A. Wu, K. Olino, Q. Xiao, Y. Chai, A. Wamwea, E. Bigelow, E. Lutz, L. Liu, S. Yao, R.A. Anders, D. Laheru, C.L. Wolfgang, B.H. Edil, R.D. Schulick, E.M. Jaffee, L. Zheng, PD-1/PD-L1 blockade together with vaccine therapy facilitates effector T-cell infiltration into pancreatic tumors, Journal of immunotherapy 38(1) (2015) 1-11.

[87] J.P. Antonios, H. Soto, R.G. Everson, J. Orpilla, D. Moughon, N. Shin, S. Sedighim, W.H. Yong, G. Li, T.F. Cloughesy, L.M. Liau, R.M. Prins, PD-1 blockade enhances the vaccination-induced immune response in glioma, JCI insight 1(10) (2016).

[88] E.R. Lutz, H. Kinkead, E.M. Jaffee, L. Zheng, Priming the pancreatic cancer tumor microenvironment for checkpoint-inhibitor immunotherapy, Oncoimmunology 3(11) (2014) e962401.

[89] E.R. Lutz, A.A. Wu, E. Bigelow, R. Sharma, G. Mo, K. Soares, S. Solt, A. Dorman, A. Wamwea, A. Yager, D. Laheru, C.L. Wolfgang, J. Wang, R.H. Hruban, R.A. Anders, E.M. Jaffee, L. Zheng, Immunotherapy converts nonimmunogenic pancreatic tumors into immunogenic foci of immune regulation, Cancer immunology research 2(7) (2014) 616-31. 
[90] C. Pfirschke, C. Engblom, S. Rickelt, V. Cortez-Retamozo, C. Garris, F. Pucci, T. Yamazaki, V. Poirier-Colame, A. Newton, Y. Redouane, Y.J. Lin, G. Wojtkiewicz, Y. Iwamoto, M. Mino-Kenudson, T.G. Huynh, R.O. Hynes, G.J. Freeman, G. Kroemer, L. Zitvogel, R. Weissleder, M.J. Pittet, Immunogenic Chemotherapy Sensitizes Tumors to Checkpoint Blockade Therapy, Immunity 44(2) (2016) 343-54.

[91] A. Snyder, V. Makarov, T. Merghoub, J. Yuan, J.M. Zaretsky, A. Desrichard, L.A. Walsh, M.A. Postow, P. Wong, T.S. Ho, T.J. Hollmann, C. Bruggeman, K. Kannan, Y. Li, C. Elipenahli, C. Liu, C.T. Harbison, L. Wang, A. Ribas, J.D. Wolchok, T.A. Chan, Genetic basis for clinical response to CTLA-4 blockade in melanoma, The New England journal of medicine 371(23) (2014) 2189-99.

[92] O. Hamid, H. Schmidt, A. Nissan, L. Ridolfi, S. Aamdal, J. Hansson, M. Guida, D.M. Hyams, H. Gomez, L. Bastholt, S.D. Chasalow, D. Berman, A prospective phase II trial exploring the association between tumor microenvironment biomarkers and clinical activity of ipilimumab in advanced melanoma, Journal of translational medicine 9 (2011) 204. [93] J.F. Grosso, M.N. Jure-Kunkel, CTLA-4 blockade in tumor models: an overview of preclinical and translational research, Cancer immunity 13 (2013) 5.

[94] A.A. Sarnaik, B. Yu, D. Yu, D. Morelli, M. Hall, D. Bogle, L. Yan, S. Targan, J. Solomon, G. Nichol, M. Yellin, J.S. Weber, Extended dose ipilimumab with a peptide vaccine: immune correlates associated with clinical benefit in patients with resected high-risk stage IIIc/IV melanoma, Clinical cancer research : an official journal of the American Association for Cancer Research 17(4) (2011) 896-906.

[95] G.T. Gibney, R.R. Kudchadkar, R.C. DeConti, M.S. Thebeau, M.P. Czupryn, L. Tetteh, C. Eysmans, A. Richards, M.J. Schell, K.J. Fisher, C.E. Horak, H.D. Inzunza, B. Yu, A.J. Martinez, I. Younos, J.S. Weber, Safety, correlative markers, and clinical results of adjuvant nivolumab in combination with vaccine in resected high-risk metastatic melanoma, Clinical cancer research : an official journal of the American Association for Cancer Research 21(4) (2015) 712-20.

[96] G. Parmiani, C. Maccalli, M. Maio, Integrating Immune Checkpoint Blockade with Anti-Neo/Mutated Antigens Reactivity to Increase the Clinical Outcome of Immunotherapy, Vaccines 3(2) (2015) 420-8.

[97] Y.C. Lu, P.F. Robbins, Targeting neoantigens for cancer immunotherapy, International immunology 28(7) (2016) 365-70.

[98] Y.C. Lu, P.F. Robbins, Cancer immunotherapy targeting neoantigens, Seminars in immunology 28(1) (2016) 22-7.

[99] M.M. Gubin, M.N. Artyomov, E.R. Mardis, R.D. Schreiber, Tumor neoantigens: building a framework for personalized cancer immunotherapy, The Journal of clinical investigation 125(9) (2015) 3413-21.

[100] S.A. Rosenberg, J.C. Yang, N.P. Restifo, Cancer immunotherapy: moving beyond current vaccines, Nature medicine 10(9) (2004) 909-15.

[101] G. Boland, J. Beran, M. Lievens, J. Sasadeusz, P. Dentico, H. Nothdurft, J.N. Zuckerman, B. Genton, R. Steffen, L. Loutan, J. Van Hattum, M. Stoffel, Safety and immunogenicity profile of an experimental hepatitis B vaccine adjuvanted with AS04, Vaccine 23(3) (2004) 316-20.

[102] M. Gunzer, H. Riemann, Y. Basoglu, A. Hillmer, C. Weishaupt, S. Balkow, B. Benninghoff, B. Ernst, M. Steinert, T. Scholzen, C. Sunderkotter, S. Grabbe, Systemic administration of a TLR7 ligand leads to transient immune incompetence due to peripheralblood leukocyte depletion, Blood 106(7) (2005) 2424-32.

[103] P. Savage, V. Horton, J. Moore, M. Owens, P. Witt, M.E. Gore, A phase I clinical trial of imiquimod, an oral interferon inducer, administered daily, British journal of cancer 74(9) (1996) 1482-6. 
[104] T. Sparwasser, T. Miethke, G. Lipford, K. Borschert, H. Hacker, K. Heeg, H. Wagner, Bacterial DNA causes septic shock, Nature 386(6623) (1997) 336-7.

[105] C.J. Voskens, S.M. Goldinger, C. Loquai, C. Robert, K.C. Kaehler, C. Berking, T. Bergmann, C.L. Bockmeyer, T. Eigentler, M. Fluck, C. Garbe, R. Gutzmer, S. Grabbe, A. Hauschild, R. Hein, G. Hundorfean, A. Justich, U. Keller, C. Klein, C. Mateus, P. Mohr, S. Paetzold, I. Satzger, D. Schadendorf, M. Schlaeppi, G. Schuler, B. Schuler-Thurner, U. Trefzer, J. Ulrich, J. Vaubel, R. von Moos, P. Weder, T. Wilhelm, D. Goppner, R. Dummer, L.M. Heinzerling, The price of tumor control: an analysis of rare side effects of anti-CTLA-4 therapy in metastatic melanoma from the ipilimumab network, PloS one 8(1) (2013) e53745. [106] J. Weber, Review: anti-CTLA-4 antibody ipilimumab: case studies of clinical response and immune-related adverse events, The oncologist 12(7) (2007) 864-72.

[107] K.A. Marrone, W. Ying, J. Naidoo, Immune-Related Adverse Events From Immune Checkpoint Inhibitors, Clinical pharmacology and therapeutics 100(3) (2016) 242-51.

[108] R.K. Jain, T. Stylianopoulos, Delivering nanomedicine to solid tumors, Nature reviews. Clinical oncology 7(11) (2010) 653-64.

[109] J. Kreuter, Encyclopaedia of Pharmaceutical Technology, Nanoparticles, Marcel Dekker Inc., New York, USA, 1994, pp. 165-190.

[110] A. Kumari, S.K. Yadav, S.C. Yadav, Biodegradable polymeric nanoparticles based drug delivery systems, Colloids and surfaces. B, Biointerfaces 75(1) (2010) 1-18.

[111] M. Benesch, C. Urban, Liposomal cytarabine for leukemic and lymphomatous meningitis: recent developments, Expert opinion on pharmacotherapy 9(2) (2008) 301-9. [112] J. Carnevale, A.H. Ko, MM-398 (nanoliposomal irinotecan): emergence of a novel therapy for the treatment of advanced pancreatic cancer, Future oncology 12(4) (2016) 45364.

[113] R.D. Hofheinz, S.U. Gnad-Vogt, U. Beyer, A. Hochhaus, Liposomal encapsulated anticancer drugs, Anti-cancer drugs 16(7) (2005) 691-707.

[114] F. Danhier, E. Ansorena, J.M. Silva, R. Coco, A. Le Breton, V. Preat, PLGA-based nanoparticles: an overview of biomedical applications, Journal of controlled release : official journal of the Controlled Release Society 161(2) (2012) 505-22.

[115] Y. Liu, H. Miyoshi, M. Nakamura, Nanomedicine for drug delivery and imaging: a promising avenue for cancer therapy and diagnosis using targeted functional nanoparticles, International journal of cancer. Journal international du cancer 120(12) (2007) 2527-37. [116] D.E. Lee, H. Koo, I.C. Sun, J.H. Ryu, K. Kim, I.C. Kwon, Multifunctional nanoparticles for multimodal imaging and theragnosis, Chemical Society reviews 41(7) (2012) 2656-72.

[117] S. Sharma, Nanotheranostics in evidence based personalized medicine, Current drug targets 15(10) (2014) 915-30.

[118] K. Cho, X. Wang, S. Nie, Z.G. Chen, D.M. Shin, Therapeutic nanoparticles for drug delivery in cancer, Clinical cancer research : an official journal of the American Association for Cancer Research 14(5) (2008) 1310-6.

[119] V. Jain, S. Jain, S.C. Mahajan, Nanomedicines based drug delivery systems for anticancer targeting and treatment, Current drug delivery 12(2) (2015) 177-91.

[120] K. Greish, Enhanced permeability and retention (EPR) effect for anticancer nanomedicine drug targeting, Methods in molecular biology 624 (2010) 25-37.

[121] M. Longmire, P.L. Choyke, H. Kobayashi, Clearance properties of nano-sized particles and molecules as imaging agents: considerations and caveats, Nanomedicine 3(5) (2008) 70317.

[122] M.J. Ernsting, M. Murakami, A. Roy, S.D. Li, Factors controlling the pharmacokinetics, biodistribution and intratumoral penetration of nanoparticles, Journal of controlled release : official journal of the Controlled Release Society 172(3) (2013) 782-94. 
[123] U. Prabhakar, H. Maeda, R.K. Jain, E.M. Sevick-Muraca, W. Zamboni, O.C. Farokhzad, S.T. Barry, A. Gabizon, P. Grodzinski, D.C. Blakey, Challenges and key considerations of the enhanced permeability and retention effect for nanomedicine drug delivery in oncology, Cancer research 73(8) (2013) 2412-7.

[124] L. Brannon-Peppas, J.O. Blanchette, Nanoparticle and targeted systems for cancer therapy, Advanced drug delivery reviews 56(11) (2004) 1649-59.

[125] B. Yu, Y. Mao, L.Y. Bai, S.E. Herman, X. Wang, A. Ramanunni, Y. Jin, X. Mo, C. Cheney, K.K. Chan, D. Jarjoura, G. Marcucci, R.J. Lee, J.C. Byrd, L.J. Lee, N. Muthusamy, Targeted nanoparticle delivery overcomes off-target immunostimulatory effects of oligonucleotides and improves therapeutic efficacy in chronic lymphocytic leukemia, Blood 121(1) (2013) 136-47.

[126] A.L. Silva, P.C. Soema, B. Slutter, F. Ossendorp, W. Jiskoot, PLGA particulate delivery systems for subunit vaccines: Linking particle properties to immunogenicity, Human vaccines \& immunotherapeutics 12(4) (2016) 1056-69.

[127] Y.R. Lee, Y.H. Lee, S.A. Im, I.H. Yang, G.W. Ahn, K. Kim, C.K. Lee, Biodegradable nanoparticles containing TLR3 or TLR9 agonists together with antigen enhance MHCrestricted presentation of the antigen, Archives of pharmacal research 33(11) (2010) 1859-66. [128] Y.R. Lee, Y.H. Lee, K.H. Kim, S.A. Im, C.K. Lee, Induction of Potent Antigenspecific Cytotoxic T Cell Response by PLGA-nanoparticles Containing Antigen and TLR Agonist, Immune network 13(1) (2013) 30-3.

[129] S. Hamdy, O. Molavi, Z. Ma, A. Haddadi, A. Alshamsan, Z. Gobti, S. Elhasi, J. Samuel, A. Lavasanifar, Co-delivery of cancer-associated antigen and Toll-like receptor 4 ligand in PLGA nanoparticles induces potent CD8+ T cell-mediated anti-tumor immunity, Vaccine 26(39) (2008) 5046-57.

[130] M. Diwan, P. Elamanchili, H. Lane, A. Gainer, J. Samuel, Biodegradable nanoparticle mediated antigen delivery to human cord blood derived dendritic cells for induction of primary T cell responses, Journal of drug targeting 11(8-10) (2003) 495-507.

[131] S. Hamdy, P. Elamanchili, A. Alshamsan, O. Molavi, T. Satou, J. Samuel, Enhanced antigen-specific primary CD4+ and CD8+ responses by codelivery of ovalbumin and toll-like receptor ligand monophosphoryl lipid A in poly(D,L-lactic-co-glycolic acid) nanoparticles, Journal of biomedical materials research. Part A 81(3) (2007) 652-62.

[132] P.O. Ilyinskii, C.J. Roy, C.P. O'Neil, E.A. Browning, L.A. Pittet, D.H. Altreuter, F. Alexis, E. Tonti, J. Shi, P.A. Basto, M. Iannacone, A.F. Radovic-Moreno, R.S. Langer, O.C. Farokhzad, U.H. von Andrian, L.P. Johnston, T.K. Kishimoto, Adjuvant-carrying synthetic vaccine particles augment the immune response to encapsulated antigen and exhibit strong local immune activation without inducing systemic cytokine release, Vaccine 32(24) (2014) 2882-95.

[133] K.P. Nikitczuk, R.S. Schloss, M.L. Yarmush, E.C. Lattime, PLGA-polymer encapsulating tumor antigen and $\mathrm{CpG}$ DNA administered into the tumor microenvironment elicits a systemic antigen-specific IFN-gamma response and enhances survival, Journal of cancer therapy 4(1) (2013) 280-290.

[134] A. de Titta, M. Ballester, Z. Julier, C. Nembrini, L. Jeanbart, A.J. van der Vlies, M.A. Swartz, J.A. Hubbell, Nanoparticle conjugation of $\mathrm{CpG}$ enhances adjuvancy for cellular immunity and memory recall at low dose, Proceedings of the National Academy of Sciences of the United States of America 110(49) (2013) 19902-7.

[135] Z. Xu, S. Ramishetti, Y.C. Tseng, S. Guo, Y. Wang, L. Huang, Multifunctional nanoparticles co-delivering Trp2 peptide and $\mathrm{CpG}$ adjuvant induce potent cytotoxic $\mathrm{T}$ lymphocyte response against melanoma and its lung metastasis, Journal of controlled release : official journal of the Controlled Release Society 172(1) (2013) 259-65. 
[136] P. Elamanchili, C.M. Lutsiak, S. Hamdy, M. Diwan, J. Samuel, "Pathogen-mimicking" nanoparticles for vaccine delivery to dendritic cells, Journal of immunotherapy 30(4) (2007) 378-95.

[137] J.R. Tisoncik, M.J. Korth, C.P. Simmons, J. Farrar, T.R. Martin, M.G. Katze, Into the eye of the cytokine storm, Microbiology and molecular biology reviews : MMBR 76(1) (2012) 16-32.

[138] L.J. Cruz, P.J. Tacken, C. Eich, F. Rueda, R. Torensma, C.G. Figdor, Controlled release of antigen and Toll-like receptor ligands from PLGA nanoparticles enhances immunogenicity, Nanomedicine 12(5) (2017) 491-510.

[139] A.L. Silva, R.A. Rosalia, A. Sazak, M.G. Carstens, F. Ossendorp, J. Oostendorp, W. Jiskoot, Optimization of encapsulation of a synthetic long peptide in PLGA nanoparticles: low-burst release is crucial for efficient CD8(+) T cell activation, European journal of pharmaceutics and biopharmaceutics : official journal of Arbeitsgemeinschaft fur Pharmazeutische Verfahrenstechnik e.V 83(3) (2013) 338-45.

[140] F. Fontana, D. Liu, J. Hirvonen, H.A. Santos, Delivery of therapeutics with nanoparticles: what's new in cancer immunotherapy?, Wiley interdisciplinary reviews. Nanomedicine and nanobiotechnology (2016).

[141] A.L. Silva, R.A. Rosalia, E. Varypataki, S. Sibuea, F. Ossendorp, W. Jiskoot, Poly(lactic-co-glycolic-acid)-based particulate vaccines: particle uptake by dendritic cells is a key parameter for immune activation, Vaccine 33(7) (2015) 847-54.

[142] L.J. Cruz, P.J. Tacken, R. Fokkink, B. Joosten, M.C. Stuart, F. Albericio, R. Torensma, C.G. Figdor, Targeted PLGA nano- but not microparticles specifically deliver antigen to human dendritic cells via DC-SIGN in vitro, Journal of controlled release : official journal of the Controlled Release Society 144(2) (2010) 118-26.

[143] R.A. Rosalia, L.J. Cruz, S. van Duikeren, A.T. Tromp, A.L. Silva, W. Jiskoot, T. de Gruijl, C. Lowik, J. Oostendorp, S.H. van der Burg, F. Ossendorp, CD40-targeted dendritic cell delivery of PLGA-nanoparticle vaccines induce potent anti-tumor responses, Biomaterials 40 (2015) 88-97.

[144] L.J. Cruz, F. Rueda, B. Cordobilla, L. Simon, L. Hosta, F. Albericio, J.C. Domingo, Targeting nanosystems to human DCs via Fc receptor as an effective strategy to deliver antigen for immunotherapy, Molecular pharmaceutics 8(1) (2011) 104-16. [145] L.J. Cruz, R.A. Rosalia, J.W. Kleinovink, F. Rueda, C.W. Lowik, F. Ossendorp, Targeting nanoparticles to CD40, DEC-205 or CD11c molecules on dendritic cells for efficient CD8(+) T cell response: a comparative study, Journal of controlled release : official journal of the Controlled Release Society 192 (2014) 209-18.

[146] P.J. Tacken, I.S. Zeelenberg, L.J. Cruz, M.A. van Hout-Kuijer, G. van de Glind, R.G. Fokkink, A.J. Lambeck, C.G. Figdor, Targeted delivery of TLR ligands to human and mouse dendritic cells strongly enhances adjuvanticity, Blood 118(26) (2011) 6836-44.

[147] A.D. Simmons, M. Moskalenko, J. Creson, J. Fang, S. Yi, M.J. VanRoey, J.P. Allison, K. Jooss, Local secretion of anti-CTLA-4 enhances the therapeutic efficacy of a cancer immunotherapy with reduced evidence of systemic autoimmunity, Cancer immunology, immunotherapy : CII 57(8) (2008) 1263-70.

[148] M.F. Fransen, T.C. van der Sluis, F. Ossendorp, R. Arens, C.J. Melief, Controlled local delivery of CTLA-4 blocking antibody induces CD8+ T-cell-dependent tumor eradication and decreases risk of toxic side effects, Clinical cancer research : an official journal of the American Association for Cancer Research 19(19) (2013) 5381-9.

[149] M.F. Fransen, M. Sluijter, H. Morreau, R. Arens, C.J. Melief, Local activation of CD8 $\mathrm{T}$ cells and systemic tumor eradication without toxicity via slow release and local delivery of agonistic CD40 antibody, Clinical cancer research : an official journal of the American Association for Cancer Research 17(8) (2011) 2270-80. 
[150] B.S. Graham, M.J. McElrath, M.C. Keefer, K. Rybczyk, D. Berger, K.J. Weinhold, J. Ottinger, G. Ferarri, D.C. Montefiori, D. Stablein, C. Smith, R. Ginsberg, J. Eldridge, A. Duerr, P. Fast, B.F. Haynes, A.V.E. Group, Immunization with cocktail of HIV-derived peptides in montanide ISA-51 is immunogenic, but causes sterile abscesses and unacceptable reactogenicity, PloS one 5(8) (2010) e11995.

[151] P.P. Leenaars, M.A. Koedam, P.W. Wester, V. Baumans, E. Claassen, C.F. Hendriksen, Assessment of side effects induced by injection of different adjuvant/antigen combinations in rabbits and mice, Laboratory animals 32(4) (1998) 387-406.

[152] C. Lei, P. Liu, B. Chen, Y. Mao, H. Engelmann, Y. Shin, J. Jaffar, I. Hellstrom, J. Liu, K.E. Hellstrom, Local release of highly loaded antibodies from functionalized nanoporous support for cancer immunotherapy, Journal of the American Chemical Society 132(20) (2010) 6906-7.

[153] S. Rahimian, M.F. Fransen, J.W. Kleinovink, M. Amidi, F. Ossendorp, W.E. Hennink, Polymeric microparticles for sustained and local delivery of antiCD40 and antiCTLA-4 in immunotherapy of cancer, Biomaterials 61 (2015) 33-40.

[154] F. Alexis, E. Pridgen, L.K. Molnar, O.C. Farokhzad, Factors affecting the clearance and biodistribution of polymeric nanoparticles, Molecular pharmaceutics 5(4) (2008) 505-15.

[155] M.F. Fransen, R.A. Cordfunke, M. Sluijter, M.J. van Steenbergen, J.W. Drijfhout, F. Ossendorp, W.E. Hennink, C.J. Melief, Effectiveness of slow-release systems in CD40 agonistic antibody immunotherapy of cancer, Vaccine 32(15) (2014) 1654-60.

[156] R. Mehvar, Dextrans for targeted and sustained delivery of therapeutic and imaging agents, Journal of controlled release : official journal of the Controlled Release Society 69(1) (2000) $1-25$.

[157] Z. Amoozgar, Y. Yeo, Recent advances in stealth coating of nanoparticle drug delivery systems, Wiley interdisciplinary reviews. Nanomedicine and nanobiotechnology 4(2) (2012) 219-33.

[158] J.V. Jokerst, T. Lobovkina, R.N. Zare, S.S. Gambhir, Nanoparticle PEGylation for imaging and therapy, Nanomedicine 6(4) (2011) 715-28.

[159] M.F. Fransen, R. Arens, C.J. Melief, Local targets for immune therapy to cancer: tumor draining lymph nodes and tumor microenvironment, International journal of cancer. Journal international du cancer 132(9) (2013) 1971-6.

[160] S.A. Broomfield, R.G. van der Most, A.C. Prosser, S. Mahendran, M.G. Tovey, M.J. Smyth, B.W. Robinson, A.J. Currie, Locally administered TLR7 agonists drive systemic antitumor immune responses that are enhanced by anti-CD40 immunotherapy, Journal of immunology 182(9) (2009) 5217-24.

[161] J.W. Kleinovink, M.F. Fransen, C.W. Lowik, F. Ossendorp, Photodynamic-Immune Checkpoint Therapy Eradicates Local and Distant Tumors by CD8+ T Cells, Cancer immunology research 5(10) (2017) 832-838.

[162] C. Jackaman, A.M. Lew, Y. Zhan, J.E. Allan, B. Koloska, P.T. Graham, B.W. Robinson, D.J. Nelson, Deliberately provoking local inflammation drives tumors to become their own protective vaccine site, International immunology 20(11) (2008) 1467-79. [163] L.J. Cruz, P.J. Tacken, I.S. Zeelenberg, M. Srinivas, F. Bonetto, B. Weigelin, C. Eich, I.J. de Vries, C.G. Figdor, Tracking targeted bimodal nanovaccines: immune responses and routing in cells, tissue, and whole organism, Molecular pharmaceutics 11(12) (2014) 4299313.

[164] A. Khong, M.D. Brown, J.B. Vivian, B.W. Robinson, A.J. Currie, Agonistic anti-CD40 antibody therapy is effective against postoperative cancer recurrence and metastasis in a murine tumor model, Journal of immunotherapy 36(7) (2013) 365-72.

[165] A. Khong, A.L. Cleaver, M. Fahmi Alatas, B.C. Wylie, T. Connor, S.A. Fisher, S. Broomfield, W.J. Lesterhuis, A.J. Currie, R.A. Lake, B.W. Robinson, The efficacy of tumor 
debulking surgery is improved by adjuvant immunotherapy using imiquimod and anti-CD40, BMC cancer 14 (2014) 969.

[166] C.G. Park, C.A. Hartl, D. Schmid, E.M. Carmona, H.J. Kim, M.S. Goldberg, Extended release of perioperative immunotherapy prevents tumor recurrence and eliminates metastases, Science translational medicine 10(433) (2018).

[167] J. Liu, S.J. Blake, M.C. Yong, H. Harjunpaa, S.F. Ngiow, K. Takeda, A. Young, J.S. O'Donnell, S. Allen, M.J. Smyth, M.W. Teng, Improved Efficacy of Neoadjuvant Compared to Adjuvant Immunotherapy to Eradicate Metastatic Disease, Cancer discovery 6(12) (2016) 1382-1399.

[168] C.H. Kapadia, J.L. Perry, S. Tian, J.C. Luft, J.M. DeSimone, Nanoparticulate immunotherapy for cancer, Journal of controlled release : official journal of the Controlled Release Society 219 (2015) 167-80.

[169] M.A. Morse, H.K. Lyerly, Checkpoint blockade in combination with cancer vaccines, Vaccine 33(51) (2015) 7377-7385.

[170] O.A. Ali, S.A. Lewin, G. Dranoff, D.J. Mooney, Vaccines Combined with Immune Checkpoint Antibodies Promote Cytotoxic T-cell Activity and Tumor Eradication, Cancer immunology research 4(2) (2016) 95-100.

[171] Q. Chen, L. Xu, C. Liang, C. Wang, R. Peng, Z. Liu, Photothermal therapy with immune-adjuvant nanoparticles together with checkpoint blockade for effective cancer immunotherapy, Nature communications 7 (2016) 13193.

[172] Z. Xu, Y. Wang, L. Zhang, L. Huang, Nanoparticle-delivered transforming growth factor-beta siRNA enhances vaccination against advanced melanoma by modifying tumor microenvironment, ACS nano 8(4) (2014) 3636-45.

[173] J. Park, S.H. Wrzesinski, E. Stern, M. Look, J. Criscione, R. Ragheb, S.M. Jay, S.L. Demento, A. Agawu, P. Licona Limon, A.F. Ferrandino, D. Gonzalez, A. Habermann, R.A. Flavell, T.M. Fahmy, Combination delivery of TGF-beta inhibitor and IL-2 by nanoscale liposomal polymeric gels enhances tumour immunotherapy, Nature materials 11(10) (2012) 895-905.

\section{Web resources}

[other]

Database of privately and publicly funded clinical studies. Available from URL: https://clinicaltrials.gov/ 